\title{
Reprogramming the neuroblastoma epigenome with a mitochondrial uncoupler
}

Haowen Jiang ${ }^{1}$, Rachel L Greathouse ${ }^{2}$, Bo He ${ }^{1}$, Yang $\mathrm{Li}^{1}$, Albert M. Li ${ }^{1,3}$, Balint Forgo ${ }^{4}$,

Michaela Yip ${ }^{1}$, Allison $\mathrm{Li}^{1}$, Moriah Shih ${ }^{1}$, Selene Banuelos ${ }^{5}$, Meng-Ning Zhou ${ }^{1}$, Joshua J. Gruber $^{6}$, Hiroyuki Shimada ${ }^{4}$, Bill Chiu ${ }^{2,7}$, Jiangbin Ye $\mathrm{e}^{1,3,7^{\star}}$

${ }^{1}$ Department of Radiation Oncology, Stanford University School of Medicine. Stanford, CA 94305, USA. '2Department of Surgery, Stanford University School of Medicine, Stanford, CA 94305, USA. ${ }^{3}$ Cancer Biology Program, Stanford University School of Medicine. ${ }^{4}$ Department of Pathology, Stanford University, Stanford, CA 94305, USA. ${ }^{5}$ Department of Genetics, Stanford University, Stanford, CA 94305, USA. ${ }^{6}$ Simmons Comprehensive Cancer Center, University of Texas Southwestern Medical Center. Dallas, TX 75235, USA. ${ }^{7}$ Stanford Cancer Institute, Stanford University School of Medicine. Stanford, CA 94305, US.

* Correspondence to: Jiangbin Ye (yej1@stanford.edu)

269 Campus Drive

Stanford, CA 94305

Tel: $650-724-7459$ 


\begin{abstract}
Dysregulated DNA methylation is associated with poor prognosis in cancer patients, promoting tumorigenesis and therapeutic resistance ${ }^{1}$. DNA methyltransferase inhibitors (DNMTi) reduce DNA methylation and promote cancer cell differentiation, with two DNMTi already approved for cancer treatment ${ }^{2}$. However, these drugs rely on cell division to dilute existing methylation, thus the 'demethylation' effects are achieved in a passive manner, limiting their application in slow-proliferating tumor cells. In this study we use a mitochondrial uncoupler, niclosamide ethanolamine (NEN), to actively achieve global DNA demethylation. NEN treatment promotes DNA demethylation by activating electron transport chain (ETC) to produce $\alpha$-ketoglutarate ( $\alpha-K G)$, a substrate for the DNA demethylase TET. In addition, NEN inhibits reductive carboxylation, a key metabolic pathway to support growth of cancer cells with defective mitochondria or under hypoxia. Importantly, NEN treatment reduces 2-hydroxyglutarate (2-HG) generation and blocks DNA hypermethylation under hypoxia. Together, these metabolic reprogramming effects of NEN actively alter the global DNA methylation landscape and promote neuroblastoma differentiation. These results not only support Warburg's original hypothesis that inhibition of ETC causes cell de-differentiation and tumorigenesis, but also suggest that mitochondrial uncoupling is an effective metabolic and epigenetic intervention that remodels the tumor epigenome for better prognosis.
\end{abstract}




\section{Materials and methods}

\section{Cell lines and culture}

CHP134, SK-N-BE(2) and NB16 cells were obtained from Dr. John M. Maris' laboratory (Children's Hospital of Philadelphia). SMS-KCNR cells were obtained from Dr. C. Patrick Reynolds' laboratory (Texas Tech University Health Sciences Center) ${ }^{3}$. Certificate of analysis is available from each group. Ovarian cancer cell line OVCAR3 was from Dr. Erinn Rankin's laboratory (Stanford University), and lung cancer cell lines H29 and H82 was from Dr. Julien Sage's laboratory (Stanford University). All cell lines were cultured in DMEM/F12 medium (Caisson Labs, DFL15) supplemented with 1\% PenicillinStreptomycin (Gibco, 15140122), 10\% FBS (Sigma, F0926) and extra 1mM glutamine (Gibco, 25030081).

\section{Protein extraction and immunoblot}

Cells were washed with ice-cold PBS buffer (Invitrogen, 20012050) and lysed with harvest buffer (10mM Hepes pH 7.9, 50mM NaCl, 500mM sucrose, 0.1mM EDTA and 0.5\% Trition X-100) supplemented with 1\% Halt inhibitors (Thermo Scientific ${ }^{\mathrm{TM}}, 78443$ ) for 10 minutes. Cell lysate was centrifuged at $3000 \mathrm{rpm}$ for $3 \mathrm{~min}$ at $4{ }^{\circ} \mathrm{C}$. The supernatant containing cytosolic proteins was transferred to a different tube. The pellet containing nuclear proteins was dissolved with nuclear lysis buffer $(10 \mathrm{mM}$ Hepes pH 7.9, 0.5M NaCl, $0.1 \mathrm{mM}$ EDTA, 0.1mM EGTA and 0.1\% NP40) supplemented with 1\% Halt inhibitors (Thermo Scientific ${ }^{\mathrm{TM}}, 78443$ ) for 5 minutes at $4{ }^{\circ} \mathrm{C}$. Then the solution was sonicated at $4^{\circ} \mathrm{C}$ for 6 cycles ( 1 cycle $=30$ s sonication and 30 s cooldown with "High" energy intensity) using a Bioruptor ${ }^{\circledR}$ Plus sonication (Diagenode, UCD-300). After sonication, the solution was centrifuged at $15,000 \mathrm{rpm}$ for 10 minutes. The supernatant was kept as nuclear extraction. Protein concentration was determined by BCA assay (Thermo Scientific, 23227). $5 \mu \mathrm{g}$ nuclear proteins or $7.5 \mu \mathrm{g}$ cytosolic proteins were boiled in loading buffer with reducing reagents (Invitrogen, NuPAGETM LDS Sample Buffer (4X), NP0007), then separated with SDS-PAGE (Nupage ${ }^{\mathrm{TM}}$ 4-12\% Bis-Tris Protein Gels, 1.0 mm, Invitrogen ${ }^{\mathrm{TM}}$, NP0322BOX). Protein was transferred onto a nitrocellulose membrane (Thermo Scientific ${ }^{\mathrm{TM}}$, 88018). After blocking in 5\% non-fat milk for 30 mintutes at room temperature (RT), the primary antibody was added for incubation overnight at $4{ }^{\circ} \mathrm{C}$. After washing with TBST (CST, \#9997, 1:10 diluted by deionized water) for 3 times, HRP-conjugated 
secondary antibodies were applied. Signals were detected with an ECL kit (Thermo Scientific ${ }^{\mathrm{TM}}$, 34577) by using BioRad Universal Hood II.

\section{RNA isolation, reverse transcription, and real-time PCR}

The procedure was performed as described before ${ }^{4}$. Briefly, total RNA was isolated from 60mm tissue culture plates according to the TRIzol Reagent (Invitrogen, 15596026) protocol. $3 \mu \mathrm{g}$ of total RNA was used in the reverse transcription reaction using the iScript cDNA synthesis kit (Bio-Rad). Quantitative PCR amplification was performed on the Prism 7900 Sequence Detection System (Applied Biosystems) using Taqman Gene Expression Assays (Applied Biosystems). Gene expression level were normalized to $18 \mathrm{~S}$ rRNA.

\section{Cell proliferation and clonogenic assay}

$2 \times 10^{4}$ cells were seeded in 12 well-plate and allowed to attached overnight. Then the cells were treated with various conditions as indicated for $48 \mathrm{~h}$ or $96 \mathrm{~h}(\mathrm{n}=3)$. After treatment, cells were counted using hemocytometer.

For clonogenic assay, 500 cells were plated in $60 \mathrm{~mm}$ dishes. After $24 \mathrm{~h}$, cells were treated with indicated conditions. After 14 days, the cells were fixed by $50 \%$ methanol in PBS for 15 minutes and stained by crystal violet staining solution (0.5\% crystal violet and 25\% methanol in PBS). The quantification was done by using countPHICS ${ }^{5}$.

\section{Neurite outgrowth assay}

The quantification of neurite was performed as described before ${ }^{6}$. Shortly, $1 \times 10^{4}$ SK-N-BE(2) and NB16 cells were plated in a 12 well-plate per well. After overnight incubation, cells were treated with various conditions as indicated for $72 \mathrm{~h}$. Then, images were taken by a Leica Florescent Microscope DMi8 in phase contrast mode (20x magnification). The lengths of the neurites were traced and quantified using the ImageJ plugin Neuronj ${ }^{7}$. For each sample, total neurite length was measured and normalized to the number of cell bodies, mean value from 3 biological replicates was reported.

\section{Immunofluorescence staining}

SK-N-BE(2) and NB16 cells were seeded into 8-champer slides (Thermo Fisher Scientific, 154534) with a density of $6 \times 10^{3}$ cells/well overnight and treated with indicated treatment for $72 \mathrm{~h}$. Cells were fixed with 4\% PFA in PBS with 0.1\% Tween-20 at RT for 30 minutes followed by permeabilization with $0.1 \%$ Triton $X-100$ in PBS at room 
temperature for 10 min. The cells were washed with PBS twice and blocked with $2.5 \%$ horse serum in PBS at RT for $1 \mathrm{~h}$. Then, cells were subjected to immunofluorescence staining with primary antibody at $4^{\circ} \mathrm{C}$ overnight. After two washes with PBS, cells were incubated with Alexa Fluor 594-conjugated anti-rabbit secondary antibody (Life Technologies) at RT for $1 \mathrm{~h}$ followed by staining with DAPI (Vector Laboratories, $\mathrm{H}-1800$ 2). Images were acquired with Leica DMi8 microscope.

\section{RNA Sequencing and bioinformatics analysis}

The total RNA from treatment groups (Ctrl and NEN treated, $n=3$ ) were extracted using Trizol reagent according to the manufacturer's instructions. The RNA-seq library was constructed and subjected to $150 \mathrm{bp}$ paired-end sequencing on an Illumina sequencing platform (Novogene). RNA-seq analysis was performed using the kallisto and sleuth analytical pipeline ${ }^{8-9}$. In brief, a transcript index was generated with reference to Ensembl version 67 for hg19. Paired-end mRNA-seq reads were pseudo-aligned using kallisto (v0.42.4) with respect to this transcript index using 100 bootstraps (-b 100) to estimate the variance of estimated transcript abundances. Transcript-level estimates were aggregated to transcripts per million (TPM) estimates for each gene, with gene names assigned from Ensembl using biomaRt. Differential gene expression analysis was performed using the sleuth $\mathrm{R}$ package across pairwise groups using Wald tests, with significant hits called with a sleuth $q$-value $<0.05$ and $\log 2$ (fold change) $>0.693$ or <0.693. Gene set enrichment analysis (GSEA) ${ }^{10-11}$ was used to examine the significantly enriched pathways by comparing the normalized data of the entire RNA seq TPM dataset between groups as indicated to Molecular Signatures Database (MSigDB v7.4). All the annotated transcripts ( 21,427 features in total) with expression values were uploaded to a locally-installed GSEA tool (version 4.1.0) and compared against the $\mathrm{H}$ : hallmark gene sets (50 gene sets).

To generate the favorable or unfavorable prognosis gene sets, Kaplan-Meier assay were employed for all the genes independently by using all 11 available neuroblastoma patient databases from R2 (https://hgserver1.amc.nl/cgi-bin/r2/main.cgi). Each gene that passes filter of Kaplan-Meier assay showed significant correlation with prognosis ( $p$-value $<0.05)$ in relevant databases. 
For functional annotation, differentially expressed genes were submitted to online Database for Annotation, Visualization and Integrated Discovery (DAVID) website (https://david.ncifcrf.gov/home.jsp) ${ }^{12-13}$. The Analyses in DAVID were performed using the default parameters.

\section{Global DNA methylation analysis}

For dot blot, $3 \times 10^{5}$ cells were plated in $60 \mathrm{~mm}$ dishes, after overnight incubation, the cells were treated with DMSO, $1 \mu \mathrm{M}$ NEN or $3.5 \mathrm{mM}$ dimethyl $\alpha$-ketoglutarate (DMKG) for $1 \mathrm{~h}$ or $3 \mathrm{~h}$. Cells were scaped in ice-cold PBS, the cell pellet were collected by centrifuging at 3000 rpm for 3 minutes. DNA samples were extracted by using PureLink ${ }^{\text {TM }}$ Genomic DNA Mini Kit (Gibco, K182001), then, they were denatured at $95^{\circ} \mathrm{C}$ for 10 minutes and placed on ice immediately for at least 5 minutes before multiple dilutions. Samples at different dilutions were immobilized on a nitrocellulose membrane (Thermo Scientific $^{\mathrm{TM}}$, 88018). Subsequently, the membranes were air-dried for 20minutes, UV cross-linked (UV stratalinker 1800, auto-crosslink mode), blocked with $5 \%$ non-fat milk for $1 \mathrm{~h}$ at RT followed by $16 \mathrm{~h}$ incubation at $4{ }^{\circ} \mathrm{C}$ with anti-5-methylcytosine (5mC) antibodies. After three washes in TBST, HRP-conjugated secondary antibodies were added and incubated for $1 \mathrm{~h}$ at RT. Signals were detected using an ECL kit (Thermo Scientific $^{\mathrm{TM}}$, 34577) on BioRad Universal Hood II. The membranes were then stained with methylene blue $(0.02 \%$ methylene blue in $300 \mathrm{Mm}$ Sodium acetate, $\mathrm{Ph} 5.3)$ to confirm equal DNA loading.

In addition, $5 \times 10^{5} \mathrm{SK}-\mathrm{N}-\mathrm{BE}(2)$ cells were plated in $60 \mathrm{~mm}$ dishes overnight, then the cells were treated by DMSO,1 $\mathrm{MM}$ NEN or 5-AZA for 3h, 6h, $24 \mathrm{~h}$ and $48 \mathrm{~h}$, respectively. DNA from the cells were collected and performed DNA extraction as described above. Quantitative analysis of global 5-mC levels was carried out with the MethylFlash Methylated DNA Quantification Kit (Epigentek, P-1030-48) according to the manufacturer's instructions. Results are presented as the percentage of methylated DNA (5-mC) to total DNA.

\section{Stable isotope tracing analysis}

For glutamine isotope tracing under normoxia, SK-N-BE(2) and NB16 cells were pretreated with DMSO or $1 \mu \mathrm{M}$ NEN for $3 \mathrm{~h}$. Then the culture medium was changed to DMEM/F-12, no glutamine (Gibco, 21331020) with $4 \mathrm{mM} \mathrm{U-}{ }^{13} \mathrm{C}_{5}$-glutamine (Cambridge 
Isotope Laboratories, CLM-1822-H) and 10\% dialyzed FBS (Gibco, 26400044) under same treatment condition as above for $2 \mathrm{~h}$. For glutamine isotope tracing under hypoxia, the SK-N-BE(2) cells were pretreated by DMSO or $1 \mu \mathrm{M}$ NEN under normoxia or hypoxia for $4 \mathrm{~h}$. Then changed the medium to DMEM/F-12, no glutamine (Gibco, 21331020) with 4mM $1-{ }^{13} \mathrm{C}$-glutamine (Cambridge Isotope Laboratories, CLM-CLM-3612-PK) and 10\% dialyzed FBS (Gibco, 26400044) for $2 \mathrm{~h}$ with same treatment under normoxia or hypoxia for $2 \mathrm{~h}$.

\section{Liquid chromatography-mass spectrometry analysis}

For the metabolomics and isotope tracing analysis, cells were washed with cold PBS, lysed in 80\% Ultra LC-MS acetonitrile (Fisher Scientific, A955-4) on ice for 15 minutes, centrifuged at $20,000 \mathrm{~g}$ for 10 minutes at $4{ }^{\circ} \mathrm{C}$, and the supernatant was subjected to mass spectrometry analysis. Liquid chromatography was performed using an 1290 Infinity LC system (Agilent, Santa Clara, US) coupled to a Q-TOF 6545 mass spectrometer (Agilent, Santa Clara, US). A hydrophilic interaction chromatography method (HILIC) with a BEH amide column $(100 \times 2.1 \mathrm{~mm}$ i.d., $1.7 \mu \mathrm{m}$; Waters $)$ was used for compound separation at $35^{\circ} \mathrm{C}$ with a flow rate of $0.3 \mathrm{ml} / \mathrm{min}$. The mobile phase $A$ consisted of $25 \mathrm{mM}$ ammonium acetate and $25 \mathrm{mM}$ ammonium hydroxide in water and the mobile phase $\mathrm{B}$ was acetonitrile. The gradient elution was 0-1 $\mathrm{min}, 85 \% \mathrm{~B}$; 1-12 min, $85 \% \mathrm{~B} \rightarrow 65 \% \mathrm{~B} ; 12-12.2 \mathrm{~min}, 65 \% \mathrm{~B} \rightarrow 40 \% \mathrm{~B} ; 12.2-15 \mathrm{~min}, 40 \% \mathrm{~B}$. After the gradient, the column was re-equilibrated at $85 \% \mathrm{~B}$ for $5 \mathrm{~min}$. The overall runtime was $20 \mathrm{~min}$, and the injection volume was $5 \mu \mathrm{L}$. Agilent Q-TOF was operated in negative mode and the relevant parameters were as follows: ion spray voltage, $3500 \mathrm{~V}$; nozzle voltage, $1000 \mathrm{~V}$; fragmentor voltage, $125 \mathrm{~V}$; drying gas flow, $11 \mathrm{~L} / \mathrm{min}$; capillary temperature, $325^{\circ} \mathrm{C}$, drying gas temperature, $350^{\circ} \mathrm{C}$; and nebulizer pressure, 40 psi. A full scan range was set at 50 to $1600(\mathrm{~m} / \mathrm{z})$. The reference mass was 119.0363 and 980.0164 . The acquisition rate was 2 spectra/s. Targeted analysis, isotopologues extraction and natural isotope abundance correction were performed by t Profinder B.10.00 (Agilent, Santa Clara, USA).

\section{Mouse orthotopic neuroblastoma model}

All mouse procedures were performed in accordance with Stanford University recommendations for the care and use of animals and were maintained and handled under protocols approved by the Institutional Animal Care and Use Committee. All 
procedures were performed with female NC nude mice (Taconic, Hudson, NY, USA) at 7 weeks of age. Procedures and ultrasound measurements (see below) were performed under general anesthesia using isoflurane inhalation. Orthotopic tumors within the adrenal gland were created as described before ${ }^{14}$. Briefly, a transverse incision was made on the left flank to locate the left adrenal gland, and $2 \mathrm{~mL}$ of phosphate buffered saline (PBS) containing $10^{4}$ SK-N-BE(2) cells were injected into the adrenal gland using a $30 \mathrm{G}$ needle. Fascia and skin were closed in separate layers. Tumor formation was monitored by non-invasive ultrasound measurements, and the animals euthanized when the tumor volume exceeded $1,000 \mathrm{~mm}^{3}$.

\section{Monitoring tumor growth with high frequency ultrasound}

After securing the mouse in a prone position, a Visual Sonics Vevo 2100 sonographic probe (Toronto, Ontario, Canada) was applied to the left flank to locate the left adrenal gland and the tumor. Serial cross-sectional images $(0.076 \mathrm{~mm}$ between images) were taken. The tumor volume was measured using the 3-D reconstruction tool (Vevo Software v1.6.0, Toronto, Ontario, Canada).

\section{Immunohistochemistry}

Unstained sections from the study cases were heated for 30 minutes in Bond ${ }^{\mathrm{TM}}$ Epitope Retrieval Solution 2 (No. AR9640; Leica Biosystems) using Leica BOND-MAXTM (Leica Microsystems), and incubated with either anti-MYCN mouse monoclonal antibody (NCM II 100at a dilution of 1:200) or anti-human MYC rabbit monoclonal antibody(clone Y69; \#1472-1; Epitomics at a dilution of 1:200) in Bond ${ }^{\mathrm{TM}}$ Primary Antibody Diluent (No. AR9352; Vision BioSystems). The counter staining with hematoxylin was performed for MYC protein staining slides, but no counterstaining was performed for MYCN protein staining slides.

\section{Statistics}

For cell proliferation and MS experiments, three biological repeats were used for data analysis. Results were represented as mean \pm SEM or mean \pm SD. The student's ttest was performed to determine the significance between groups (two-tailed, unequal variance). 


\section{Introduction}

Growing evidence points to the critical role of dysregulated epigenetics in promoting cancer progression ${ }^{15-18}$. Particularly, CpG islands hypermethylation in promoter region leads to the silencing of tumor suppressors, cell differentiation markers associated with poor prognosis in cancer patients, and therapeutic resistance ${ }^{19-22}$.

Unlike genetic mutations, epigenetic changes are reversible. Thus, CpG island hypermethylation has become an attractive target for cancer therapy. The DNA methyltransferase inhibitors (DNMTi) azacitidine and decitabine have shown promising effect in clinical trials and have been approved by the FDA and EMA to treat hematopoietic malignancies ${ }^{23-25}$. Nonetheless, there are several limitations of using DNMTi in clinic. First, they only block methylation on newly synthesized DNA strands rather than remove methyl groups from existing methylated CpG islands ${ }^{26}$. Second, DNMTi are considered as week mutagen since they incorporate into DNA ${ }^{26}$. Third, they cause myelosuppression and gastrointestinal toxicities ${ }^{2}$. These limitations prompt a need to identify more effective and safer strategies to target DNA hypermethylation for cancer therapy.

DNA demethylation in mammals is achieved through TET enzyme-mediated sequential oxidation of 5-methylcytosine (5-mC) to 5-hydroxymethylcytosine (5-hmC), 5formylcytosine (5-fC) and then 5-carboxylcytosine (5-caC), followed by thymine DNA glycosylase (TDG)-mediated excision of 5-fC and 5-caC coupled with base excision repair $^{27}$. This multi-step DNA demethylation process requires the co-substrate $\alpha-$ ketoglutarate ( $\alpha-K G)$, a tricarboxylic acid (TCA) cycle intermediate that can be generated from glucose or glutamine ${ }^{28}$. However, under hypoxia, $\alpha-K G$ is reduced and converted to 2-hydroxyglutarate (2-HG) as a an oncometabolite due to a reduced NAD ${ }^{+} / \mathrm{NADH}$ ratio 29-33, thus inhibiting TET ${ }^{34}$. Based on these discoveries, we hypothesize that DNA hypermethylation would be reversed by increasing the intracellular NAD $/$ NADH ratio, thus, restoring the redox homoeostasis. Consequently, the aberrant metabolic and epigenetic phenotypes of cancer cells could be corrected.

The electron transport chain (ETC) is the major site for cells to regenerate NAD ${ }^{+}$ from NADH. We hypothesize that ETC activation by mitochondrial uncoupler would 
increases the $\mathrm{NAD}^{+} / \mathrm{NADH}$ ratio, leading to an increase of the $\alpha K G / 2 \mathrm{HG}$ ratio. One of them, niclosamide ethanolamine (NEN) facilitates proton influx across the mitochondrial inner membrane without generating ATP to activate the electron transport chain (ETC) 35-36. In this study, we use NEN to reprogram the metabolism and epigenetic landscape of cancer cells. We have found that NEN treatment increases the intracellular $\mathrm{NAD}^{+} / \mathrm{NADH}$ ratio, $\alpha \mathrm{KG} / 2 \mathrm{HG}$ ratio, and pyruvate/lactate ratio. This metabolic reprogramming reduces global DNA methylation and activates differentiation-related gene expression. N-Myc, an oncogenic transcription factor often amplified in neuroblastoma (NB) and is associated with worse patient survival, is downregulated by NEN treatment. Furthermore, NEN treatment inhibits reductive carboxylation, a key metabolic pathway that converts $\alpha-K G$ to citrate to support cancer cell growth upon ETC inhibition ${ }^{31,37}$. Importantly, NEN treatment reduces 2 HG-mediated DNA hypermethylation under hypoxia. Together, these results uncover a new role of mitochondrial uncoupling as an epigenetic intervention that promotes DNA demethylation and tumor cells differentiation. 


\section{Results}

\section{Mitochondrial uncoupling increased intracellular $\alpha-K G$ and $\alpha-K G / 2-H G$ ratio}

Mitochondrial uncoupling is a process that dissipates the proton gradient across the inner mitochondrial membrane, activating the ETC to promote NADH oxidation ${ }^{38-40 .}$ Niclosamide ethanolamine (NEN) is a salt form of the FDA-approved mitochondrial uncoupler drug niclosamide with an excellent safety profile ${ }^{41-44}$. As expected, NEN treatment increased ADP/ATP and AMPIATP ratios (Figure S1a, b). Importantly, NEN treatment increased intracellular $\mathrm{NAD}^{+} / \mathrm{NADH}$ ratio in both $\mathrm{SK}-\mathrm{N}-\mathrm{BE}(2)$ and $\mathrm{NB} 16$ cells (Figure $1 \mathrm{a}, \mathrm{b}$ ). In addition, the pyruvate/lactate ratio, determined by the $\mathrm{NAD}^{+} / \mathrm{NADH}$ ratio $^{45}$, was also increased upon NEN treatment, indicating inhibition of the Warburg effect (Figure 1a, b). Furthermore, NEN treatment did not cause oxidative stress in our experimental setting based on the observation that NEN did not reduce the glutathione $(\mathrm{GSH})$ /glutathione disulfide (GSSG) ratio in neither SK-N-BE(2) nor NB16 cells (Figure S1a, b).

Because multiple key reactions in TCA cycle use NAD ${ }^{+}$as an electron acceptor, a high $\mathrm{NAD}^{+} / \mathrm{NADH}$ ratio is the major driving force for TCA cycle (Figure 1c). We next examined how mitochondrial uncoupling regulates TCA cycle metabolite levels. As the product of the first step of TCA cycle, citrate was not affected by NEN treatment (Figure S1). Surprisingly, intracellular $\alpha-K G$ levels increased significantly in both cell lines after NEN treatment (Figure 1a, b). Succinate also accumulated under NEN treatment while the aKG/succinate ratio stayed unchanged (Figure S1a, b), and no significant increase of either fumarate or malate was observed after NEN treatment (Figure S1a, b). Aspartate, which is derived from oxaloacetate, also accumulated after NEN treatment (Figure S1a, b). Because glutamine and glutamate provide the carbon backbone to generate $\alpha-K G$, we wondered whether the increased $\alpha-K G$ originated from glutamine. NEN treatment significantly reduced the intracellular glutamine and glutamate levels, suggesting the acceleration of glutaminolysis by mitochondrial uncoupling (Figure 1d).

To determine how mitochondrial uncoupling alters the glutamine flux into TCA cycle, we carried out $\left[\mathrm{U}^{13} \mathrm{C}_{5}\right]$-glutamine tracing assay (Figure $1 \mathrm{c}$ ). Surprisingly, in SK-N- 
$\mathrm{BE}(2)$ cells, no significant increase of $\mathrm{m}+5 \alpha-K G$ was observed. However, the labelling percentage of $m+3$ ( $2^{\text {nd }}$ cycle) and $m+1 / 2\left(3^{\text {rd }}\right.$ cycle) $\alpha-K G$ significantly increased upon NEN treatment (Figure 1d,e). Also, the labelling abundance of $m+2\left(2^{\text {nd }}\right.$ cycle) and $m+1 / 2\left(3^{\text {rd }}\right.$ cycle) succinate and aspartate (from oxaloacetate) significantly increased under NEN treatment (Figure S2a), suggesting that NEN treatment accelerates the of TCA cycle flux in the oxidative direction. Importantly, the m+5 labelling abundance of 2HG was significantly decreased by NEN treatment in SK-N-BE(2) cells (Figure 1e). The ratio of $m+5 \alpha-K G / m+52-H G$ decreased under NEN treatment (Figure 1e), indicating that NEN inhibits the conversion of $\alpha-K G$ to $2-H G$. In NB16 cells, no significant reduction of m+5 2-HG was observed, possibly due to the lower 2-HG generation in this cell line (Figure 1e). The increased $m+5$ and $m+3$ labeling from glutamine accounted for the $\alpha-$ KG increase (Figure 1e), and was associated with increased $m+4$ succinate and $m+4$ aspartate (Figure S2b). We also tested the metabolic reprograming effect of NEN on other cancer cell lines, including an ovarian cancer cell line OVCAR3, and two lung cancer cell lines $\mathrm{H} 29$ and H82. All the cell lines showed similar metabolic reprograming effects, featured by the increased ADP/ATP ratio and $\alpha-\mathrm{KG} / 2-\mathrm{HG}$ ratio, indicating that this is a universal metabolic reprogramming effect shared by multiple cancer types (Figure S3). Together, these data suggest that NEN treatment upregulates cellular $\alpha-K G$ through two potential mechanisms: accelerating glutaminolysis and blocking the conversion of $\alpha-K G$ to 2-HG.

\section{Mitochondrial uncoupling decreases global DNA methylation and promotes neuroblastoma cell differentiation}

Increased intracellular $\alpha-K G$ levels due to mitochondrial uncoupling may promote DNA demethylation. Indeed, NEN treatment reduced global DNA methylation in NB16 cells, as determined by dot blot (Figure 2a). To directly increase intracellular $\alpha-\mathrm{KG}$, a cellpermeable form of $\alpha-K G$, dimethyl a-ketoglutarate (DMKG) were used, and it also reduced global DNA methylation (Figure 2a). To capture the dynamic changes of global DNA methylation, we used an ELISA-based kit to quantify the DNA methylation in cells treated by NEN or a DNMTi 5-Azacytidine (5-Aza) at various time points. We found that NEN reduced the global DNA methylation faster at early time points ( $1 \mathrm{~h}$ and $3 \mathrm{~h}$ ) than 5- 
Aza (Figure 2b), possibly because NEN promotes active demethylation instead of passively blocking methylation, a process that requires cell division and DNA replication.

To investigate how NEN treatment alters the global gene expression profile, we performed RNA-seq in SK-N-BE(2) cells treated with DMSO or NEN for $16 \mathrm{~h}$. Corresponding to the DNA demethylation effect of NEN, 495 genes were significantly upregulated while 224 genes were downregulated by NEN treatment with a sleuth qvalue $<0.05$ and fold change estimate $b>a b s(\ln (2))$ (Figure $2 c)$. The upregulated genes were enriched in multiple pathways including neurogenesis, nervous system development and neuron differentiation (Figure 2d). Consistent with the pathway enrichment result, NEN treatment induced neuron differentiation morphology change in both SK-NE-BE(2) and NB16 cells, as determined by the neurite length measurement and immunofluorescence staining against neuron differentiation marker $\beta$-tubulin III (Figure 2e and f). In contrast, the NEN-downregulated genes were enriched in pathways involved in DNA replication and cell cycle progression (Figure 2g). As expected, NEN treatment significantly inhibited cell proliferation (Figure 2h). In addition, Gene Set Enrichment Analysis (GSEA) of the RNA-seq results showed that NEN treatment significantly deviated from two important cell division hallmark "E2F-TARGETS" and "G2M_CHECKPOINT" when compared to control (CTRL) treatment (Figure 2i), indicating downregulation of cell division-related genes. Intriguingly, it was reported that E2Fs transcriptionally upregulates $M Y C N^{46}$, the key oncogenic factor that is amplified in neuroblastoma and associated with poor patient outcome. NEN treatment significantly reduced the mRNA and protein level of N-Myc (Figure 3j). Consistent with the reduced NMyc protein levels, GESA analysis showed that NEN treatment significantly deviated from hallmark "MYC_TARGETS_V1" and "MYC_TARGETS_V2" when compared to control (CTRL) treatment (Figure 3k), indicating that NEN reduced the expression N-Myc targeted genes.

\section{Mitochondrial uncoupling inhibits reductive carboxylation}

Cancer cells under hypoxia or carrying mutations that suppress mitochondrial function display reductive carboxylation ${ }^{47-49}$, a reaction that converts $\alpha-K G$ to citrate to provide acetyl-CoA for lipid synthesis (Figure $3 a$ ). In the $\mathrm{U}^{13} \mathrm{C}_{5}$-glutamine tracing assay, 
we found that NEN treatment significantly inhibited reductive carboxylation flux, as determined by the decreased labelling faction of $m+5$ citrate, $m+3$ fumarate, and $m+3$ malate (Figure 3b). We next tested whether mitochondrial uncoupling could also reverse reductive carboxylation under hypoxia. When $\left[1^{13} \mathrm{C}\right]$-glutamine is used as a tracer, labelling carbon will only be detected in metabolites from the reductive carboxylation pathway ( $m+1$ citrate, $m+1$ fumarate, $m+1$ malate, and $m+1$ aspartate) (Figure 3a). NEN treatment not only reduced basal reductive carboxylation flux under normoxia, but also fully repressed hypoxia-induced reductive carboxylation flux (Figure 3c), indicating that the mitochondrial uncoupler NEN is an effective inhibitor of reductive carboxylation.

\section{Mitochondrial uncoupling inhibits 2-HG generation and DNA hypermethylation under hypoxia}

Clinically, tumor hypoxia is a significant obstacle to treatment because hypoxic tumor cells are more resistant to radiation ${ }^{50-51}$ and chemotherapy ${ }^{52-54}$. Under hypoxia, due to reduced $\mathrm{NAD}^{+} / \mathrm{NADH}$ ratio, $\alpha-K G$ is reduced and converted to L-2-HG ${ }^{29-30}$, which may repress $\alpha-K G-d e p e n d e n t$ dioxygenase, including TET DNA demethylase. We found that NEN treatment could partially restore $\mathrm{NAD}^{+} / \mathrm{NADH}$ and pyruvate/lactate ratios under hypoxia (Figure 4a). Importantly, NEN treatment partially restored $\alpha-K G$ and significantly reduced 2-HG levels under hypoxia (Figure 4a). Our previous study showed that in neuroblastoma cells, hypoxia treatment inhibited neuroblastoma cell differentiation, which could not be restore by $\alpha-K G$ supplementation ${ }^{6}$, possibly because supplemented $\alpha-K G$ was converted to $2-\mathrm{HG}^{29}$. Intriguingly, DNA hypermethylation induced by hypoxia could be repressed by NEN but not $\alpha K G$, suggests that NEN supplementation has an advantage in demethylating DNA over $\alpha-K G$ supplementation under hypoxia (Figure 4b), because NEN treatment reduces while $\alpha-K G$ increases 2-HG under hypoxia (Figure 4c). In addition, NEN supplementation can induce differentiation under hypoxia (Figure 4d). Importantly, we found that 4 days hypoxia pretreatment increased cell proliferation when the cells were replated under normoxia condition (with no treatment). However, when cells were pretreated under hypoxia with NEN, this gain of proliferation advantage from hypoxia pretreatment is blocked (Figure 4c). 


\section{NEN supplementation inhibits growth of orthotropic neuroblastoma in vivo}

Next, we examined whether NEN has anti-growth effect in vivo using an orthotopic neuroblastoma xenograft model. Because intraperitoneal injection of NEN shows poor plasma pharmacokinetics (Figure S4a), we used diet which contain 2000ppm NEN for treatment delivery ${ }^{55}$. LC/MS analysis indicated that dietary NEN supplementation led to

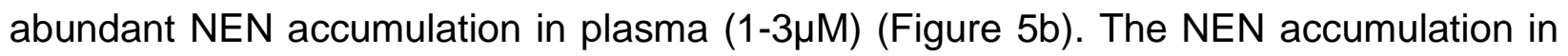
xenograft tumors is comparable to levels found in the kidney, although lower than levels in the liver (Figure 5c). NEN supplementation significantly slowed tumor growth as compared to control group (Figure 5d). Furthermore, tumor cells from NEN-treated group had much fewer enlarged prominent nucleoli (Figure 5e), which indicates active ribosome biogenesis and worse prognosis in NB patients ${ }^{56}$. Importantly, N-Myc protein expression was significantly reduced in the NEN-treated xenografts (Figure 4f). This is consistent with our in vitro observation (Figure 2j and k).

\section{NEN-induced gene expression changes indicate favorable prognosis in neuroblastoma patients}

To further explore the clinical relevance of NEN-induced gene expression profile changes, we integrated the gene expression signature of RNA-seq result from NEN treatment experiment and 11 neuroblastoma patient gene expression profile from R2 database. Using the datasets from R2 database, we generated gene sets that indicated favorable prognosis or unfavorable prognosis from the 11 neuroblastoma patient studies (The p-value of Kaplan-Meier analysis of each gene is less than 0.05). Consequently, these gene sets were defined as pathways for GSEA analysis. Surprisingly, NENupregulated genes are enriched in all the favorable prognosis gene sets except one (Figure 6a, b). In contrast, NEN-downregulated genes are enriched in unfavorable prognosis gene sets (Figure 6a, b). The only exception is that NEN-upregulated genes are enriched in an unfavorable prognosis gene set derived from N-Myc non-amplification neuroblastomas. A potential explanation for this discrepancy is that the RNA-seq data was generated from SK-N-BE(2) cells, which are N-Myc-amplified(Figure 2k). In addition, we constructed sets of overlapped genes from 7 gene sets that contain more than 1000 genes; namely, an overlapped "favorable prognosis gene set" with 286 genes and an 
overlapped "unfavorable prognosis gene set" with 270 genes (Figure 6c, d). These two genes set were submitted to pathway enrichment through online Database for Annotation, Visualization and Integrated Discovery (DAVID) analysis. The overlapped favorable prognosis gene sets were enriched for multiple neuron differentiation terms while the overlapped unfavorable prognosis gene sets were enriched for cell-cycle related terms (Figure $6 \mathrm{c}, \mathrm{d}$ ). Together these data suggest that NEN treatment reprograms the transcriptome to a gene expression profile that is associated with favorable prognosis in patients with N-Myc-amplified neuroblastoma. 


\section{Discussion}

Since Otto H. Warburg discovered that tumor cells have a high glucose consumption rate and produce large amounts of lactate in 1920 s $^{57}$, oncologists have been interested in how tumor cells alters metabolic pathways to obtain advantages during cancer progression. In one of Warburg's milestone reviews, he proposed that the cause of the Warburg effect was injury of respiration and as a consequence, cell dedifferentiation ${ }^{58}$. At that time, although he was aware that the inhibition of respiration led to metabolic reprograming and insightfully proposed a connection between metabolic reprograming and cell dedifferentiation. However, the underlying mechanism was unclear due to the field's limited understanding of metabolic control of epigenetics.

Inhibition of respiration is essentially the inhibition of the ETC, whose function is to oxidizes cellular NADH to $\mathrm{NAD}^{+}$. ETC inhibition leads to reduction of $\mathrm{NAD}^{+} / \mathrm{NADH}$ ratio. Low $\mathrm{NAD}^{+} / \mathrm{NADH}$ ratio not only drives lactate production from pyruvate to enhance the Warburg effect, but also disrupts TCA cycle flux, promoting reduction of $\alpha-K G$ to form L2-HG 29-30. Similar to the D-2-HG produced from tumors carrying IDH1/2 mutation 59-60, L2-HG also inhibits $\alpha-K G$-dependent deoxygenases, including TET enzymes and JMJDs ${ }^{61}$, leading to DNA and histone hypermethylation ${ }^{29,} 62$. It was shown that this hypermethylation phenotype blocks cell differentiation, promoting tumor progression ${ }^{63-64}$. Here we demonstrated that treatment using a mitochondrial uncoupler NEN effectively increased cellular $\alpha-K G$ levels in neuroblastoma cells to promote differentiation. NEN treatment increased $\mathrm{NAD}^{+} / \mathrm{NADH}$ ratio, which not only drives accelerated glutaminolysis to upregulate $\alpha-K G$, but also blocks the conversion of $\alpha-K G$ to $2-H G$. Together these data indicate that Warburg's origin hypothesis was correct: the ETC activity is essential to cell differentiation. Surprisingly, even under hypoxia, NEN treatment is still effective in restoring $\alpha-K G$ and reducing 2-HG levels, suggesting that NEN supplementation has an advantage in demethylation in vivo over $\alpha-K G$ supplementation.

$\mathrm{N}$-myc is the major oncogene amplified in NB. High N-myc expression is one key prognosis marker indicating poor survival in neuroblastoma patients. $\mathrm{N}$-myc is downregulated upon induction of differentiation in neuroblastoma cells ${ }^{65}$, suggesting a negative correlation between N-myc amplification and NB cell differentiation. Here we 
shown that mitochondrial uncoupler treatment could diminish the 'undruggable' N-Myc expression, highlighting the therapeutic potential in high grade neuroblastoma patients.

ETC inhibition not only promotes 2-HG production to reprogram the epigenome, but also induces reductive carboxylation flux. The citrate generated from $\alpha-K G$ provide acetyl-CoA for lipid synthesis, which is important for cell proliferation. Our data demonstrated not only that NEN treatment reversed this process, but it also increased cellular $\alpha-K G$ levels, suggesting that in addition to promoting proliferation by helping lipid synthesis, another important consequence of reductive carboxylation is to decrease intracellular $\alpha-K G$ levels and induce DNA hypermethylation.

In addition to aKG upregulation, mitochondrial uncoupler treatment caused global metabolic reprograming, including increasing $\mathrm{NAD}^{+} / \mathrm{NADH}$ ratio, AMP/ATP ratio, etc. These metabolic changes may further alter other signaling pathways that depends on $\mathrm{NAD}^{+}$or ATP to remodel epigenetics and change cell fate. In summary, we have shown that NEN, a single agent, has extensive anti-tumor effects both in vitro and in vivo, by its ability to activate ETC. Upon ETC inhibition, altered metabolism causes global changes to epigenetic modification and signaling pathway rather than affecting a single gene or pathway. Thus, it is expected that activating ETC with mitochondrial uncouplers is an effective way of reversing this process and restoring the global metabolome and epigenome, which ultimately redirects the tumor cell into a differentiated state.

\section{Acknowledgement}

This work was supported by a Stanford Maternal and Child Health Research Institute Research Scholar Award (2020) and an American Cancer Society Research Scholar Grant (RSG-20-036-01) to J.Y. 


\section{References}

1. Jones, P. A.; Issa, J. P.; Baylin, S., Targeting the cancer epigenome for therapy. Nat Rev Genet 2016, $17(10), 630-41$.

2. Derissen, E. J.; Beijnen, J. H.; Schellens, J. H., Concise drug review: azacitidine and decitabine. Oncologist 2013, 18 (5), 619-24.

3. Reynolds, C.; Biedler, J.; Spengler, B.; Reynolds, D.; Ross, R.; Frenkel, E.; Smith, R., Characterization of human neuroblastoma cell lines established before and after therapy. Journal of the National Cancer Institute 1986, 76 (3), 375-387.

4. $\quad$ Li, A. M.; Ducker, G. S.; Li, Y.; Seoane, J. A.; Xiao, Y.; Melemenidis, S.; Zhou, Y.; Liu, L.; Vanharanta, S.; Graves, E. E.; Rankin, E. B.; Curtis, C.; Massague, J.; Rabinowitz, J. D.; Thompson, C. B.; Ye, J., Metabolic Profiling Reveals a Dependency of Human Metastatic Breast Cancer on Mitochondrial Serine and One-Carbon Unit Metabolism. Mol Cancer Res 2020, 18 (4), 599-611.

5. Brzozowska, B.; Gałecki, M.; Tartas, A.; Ginter, J.; Kaźmierczak, U.; Lundholm, L., Freeware tool for analysing numbers and sizes of cell colonies. Radiation and Environmental Biophysics 2019, 58 (1), 109-117.

6. Li, Y.; Gruber, J. J.; Litzenburger, U. M.; Zhou, Y.; Miao, Y. R.; LaGory, E. L.; Li, A. M.; Hu, Z.; Yip, M.; Hart, L. S.; Maris, J. M.; Chang, H. Y.; Giaccia, A. J.; Ye, J., Acetate supplementation restores chromatin accessibility and promotes tumor cell differentiation under hypoxia. Cell Death Dis 2020, 11 (2), 102.

7. Meijering, E.; Jacob, M.; Sarria, J. C.; Steiner, P.; Hirling, H.; Unser, M., Design and validation of a tool for neurite tracing and analysis in fluorescence microscopy images. Cytometry Part $A$ : the journal of the International Society for Analytical Cytology 2004, 58 (2), 167-176.

8. Bray, N. L.; Pimentel, H.; Melsted, P.; Pachter, L., Near-optimal probabilistic RNA-seq quantification. Nature biotechnology 2016, 34 (5), 525-527.

9. Pimentel, H.; Bray, N. L.; Puente, S.; Melsted, P.; Pachter, L., Differential analysis of RNA-seq incorporating quantification uncertainty. Nature methods 2017, 14 (7), 687.

10. Mootha, V. K.; Lindgren, C. M.; Eriksson, K.-F.; Subramanian, A.; Sihag, S.; Lehar, J.; Puigserver, P.; Carlsson, E.; Ridderstråle, M.; Laurila, E., PGC-1 $\alpha$-responsive genes involved in oxidative phosphorylation are coordinately downregulated in human diabetes. Nature genetics $\mathbf{2 0 0 3}, 34$ (3), 267273.

11. Subramanian, A.; Tamayo, P.; Mootha, V. K.; Mukherjee, S.; Ebert, B. L.; Gillette, M. A.; Paulovich, A.; Pomeroy, S. L.; Golub, T. R.; Lander, E. S., Gene set enrichment analysis: a knowledgebased approach for interpreting genome-wide expression profiles. Proceedings of the National Academy of Sciences 2005, 102 (43), 15545-15550.

12. Huang, D. W.; Sherman, B. T.; Lempicki, R. A., Bioinformatics enrichment tools: paths toward the comprehensive functional analysis of large gene lists. Nucleic acids research 2009, 37 (1), 1-13.

13. Sherman, B. T.; Lempicki, R. A., Systematic and integrative analysis of large gene lists using DAVID bioinformatics resources. Nature protocols 2009, 4 (1), 44.

14. Chiu, B.; Coburn, J.; Pilichowska, M.; Holcroft, C.; Seib, F. P.; Charest, A.; Kaplan, D. L., Surgery combined with controlled-release doxorubicin silk films as a treatment strategy in an orthotopic neuroblastoma mouse model. Br J Cancer 2014, 111 (4), 708-15.

15. Takeshima, H.; Ushijima, T., Accumulation of genetic and epigenetic alterations in normal cells and cancer risk. NPJ Precis Oncol 2019, 3, 7.

16. You, J. S.; Jones, P. A., Cancer genetics and epigenetics: two sides of the same coin? Cancer Cell 2012, 22 (1), 9-20.

17. Kinnaird, A.; Zhao, S.; Wellen, K. E.; Michelakis, E. D., Metabolic control of epigenetics in cancer. Nat Rev Cancer 2016, 16 (11), 694-707. 
18. Ehrlich, M., DNA hypermethylation in disease: mechanisms and clinical relevance. Epigenetics 2019, 14 (12), 1141-1163.

19. Henrich, K. O.; Bender, S.; Saadati, M.; Dreidax, D.; Gartlgruber, M.; Shao, C.; Herrmann, C.; Wiesenfarth, M.; Parzonka, M.; Wehrmann, L.; Fischer, M.; Duffy, D. J.; Bell, E.; Torkov, A.; Schmezer, P.; Plass, C.; Hofer, T.; Benner, A.; Pfister, S. M.; Westermann, F., Integrative Genome-Scale Analysis Identifies Epigenetic Mechanisms of Transcriptional Deregulation in Unfavorable Neuroblastomas. Cancer Res 2016, 76 (18), 5523-37.

20. Koch, A.; Joosten, S. C.; Feng, Z.; de Ruijter, T. C.; Draht, M. X.; Melotte, V.; Smits, K. M.; Veeck, J.; Herman, J. G.; Van Neste, L.; Van Criekinge, W.; De Meyer, T.; van Engeland, M., Analysis of DNA methylation in cancer: location revisited. Nat Rev Clin Oncol 2018, 15 (7), 459-466.

21. Weisenberger, D. J.; Liang, G.; Lenz, H. J., DNA methylation aberrancies delineate clinically distinct subsets of colorectal cancer and provide novel targets for epigenetic therapies. Oncogene 2018, 37 (5), 566-577.

22. Bennett, R. L.; Licht, J. D., Targeting Epigenetics in Cancer. Annu Rev Pharmacol Toxicol 2018, 58, 187-207.

23. Derissen, E. J.; Beijnen, J. H.; Schellens, J. H., Concise drug review: azacitidine and decitabine. The oncologist 2013, 18 (5), 619.

24. Jones, P. A.; Issa, J.-P. J.; Baylin, S., Targeting the cancer epigenome for therapy. Nature Reviews Genetics 2016, 17 (10), 630.

25. Linnekamp, J.; Butter, R.; Spijker, R.; Medema, J.; Van Laarhoven, H., Clinical and biological effects of demethylating agents on solid tumours-a systematic review. Cancer Treatment Reviews 2017, $54,10-23$.

26. Jones, P. A.; Taylor, S. M.; Wilson, V., DNA modification, differentiation, and transformation. J Exp Zool 1983, 228 (2), 287-95.

27. Wu, X.; Zhang, Y., TET-mediated active DNA demethylation: mechanism, function and beyond. Nature Reviews Genetics 2017, 18 (9), 517.

28. Carey, B. W.; Finley, L. W.; Cross, J. R.; Allis, C. D.; Thompson, C. B., Intracellular alphaketoglutarate maintains the pluripotency of embryonic stem cells. Nature 2015, 518 (7539), 413-6.

29. Intlekofer, A. M.; Dematteo, R. G.; Venneti, S.; Finley, L. W.; Lu, C.; Judkins, A. R.; Rustenburg, A. S.; Grinaway, P. B.; Chodera, J. D.; Cross, J. R.; Thompson, C. B., Hypoxia Induces Production of L-2Hydroxyglutarate. Cell Metab 2015, 22 (2), 304-11.

30. Oldham, W. M.; Clish, C. B.; Yang, Y.; Loscalzo, J., Hypoxia-Mediated Increases in L-2hydroxyglutarate Coordinate the Metabolic Response to Reductive Stress. Cell Metab 2015, 22 (2), 291303.

31. Wise, D. R.; Ward, P. S.; Shay, J. E.; Cross, J. R.; Gruber, J. J.; Sachdeva, U. M.; Platt, J. M.; DeMatteo, R. G.; Simon, M. C.; Thompson, C. B., Hypoxia promotes isocitrate dehydrogenase-dependent carboxylation of $\alpha$-ketoglutarate to citrate to support cell growth and viability. Proceedings of the National Academy of Sciences 2011, 108 (49), 19611-19616.

32. Fendt, S.-M.; Bell, E. L.; Keibler, M. A.; Olenchock, B. A.; Mayers, J. R.; Wasylenko, T. M.; Vokes, N. I.; Guarente, L.; Vander Heiden, M. G.; Stephanopoulos, G., Reductive glutamine metabolism is a function of the $\alpha$-ketoglutarate to citrate ratio in cells. Nature communications 2013, 4 (1), 1-11.

33. Intlekofer, A. M.; Dematteo, R. G.; Venneti, S.; Finley, L. W.; Lu, C.; Judkins, A. R.; Rustenburg, A. S.; Grinaway, P. B.; Chodera, J. D.; Cross, J. R., Hypoxia induces production of L-2-hydroxyglutarate. Cell metabolism 2015, 22 (2), 304-311.

34. Xu, W.; Yang, H.; Liu, Y.; Yang, Y.; Wang, P.; Kim, S.-H.; Ito, S.; Yang, C.; Wang, P.; Xiao, M.-T., Oncometabolite 2-hydroxyglutarate is a competitive inhibitor of $\alpha$-ketoglutarate-dependent dioxygenases. Cancer cell 2011, 19 (1), 17-30. 
35. Tao, H.; Zhang, Y.; Zeng, X.; Shulman, G. I.; Jin, S., Niclosamide ethanolamine-induced mild mitochondrial uncoupling improves diabetic symptoms in mice. Nature medicine 2014, 20 (11), 1263.

36. Alasadi, A.; Chen, M.; Swapna, G.; Tao, H.; Guo, J.; Collantes, J.; Fadhil, N.; Montelione, G. T.; Jin, S., Effect of mitochondrial uncouplers niclosamide ethanolamine (NEN) and oxyclozanide on hepatic metastasis of colon cancer. Cell death \& disease 2018, 9 (2), 1-14.

37. Mullen, A. R.; Wheaton, W. W.; Jin, E. S.; Chen, P.-H.; Sullivan, L. B.; Cheng, T.; Yang, Y.; Linehan, W. M.; Chandel, N. S.; DeBerardinis, R. J., Reductive carboxylation supports growth in tumour cells with defective mitochondria. Nature 2012, 481 (7381), 385-388.

38. Alasadi, A.; Chen, M.; Swapna, G. V. T.; Tao, H.; Guo, J.; Collantes, J.; Fadhil, N.; Montelione, G. T.; Jin, S., Effect of mitochondrial uncouplers niclosamide ethanolamine (NEN) and oxyclozanide on hepatic metastasis of colon cancer. Cell Death Dis 2018, 9 (2), 215.

39. Jastroch, M.; Divakaruni, A. S.; Mookerjee, S.; Treberg, J. R.; Brand, M. D., Mitochondrial proton and electron leaks. Essays Biochem 2010, 47, 53-67.

40. Xie, N.; Zhang, L.; Gao, W.; Huang, C.; Huber, P. E.; Zhou, X.; Li, C.; Shen, G.; Zou, B., NAD(+) metabolism: pathophysiologic mechanisms and therapeutic potential. Signal Transduct Target Ther 2020, 5 (1), 227.

41. Hecht, G.; Gloxhuber, C., Studies on the tolerance of 5, 2'-dichloro-4'-nitrosalicylanilide ethanolamine salt. Zeitschrift fur Tropenmedizin und Parasitologie 1962, 13, 1-8.

42. Sheth, U., Mechanisms of anthelmintic action. Progress in Drug Research/Fortschritte der Arzneimittelforschung/Progrès des recherches pharmaceutiques 1975, 147-157.

43. Andrews, P.; Thyssen, J.; Lorke, D., The biology and toxicology of molluscicides, Bayluscide. Pharmacology \& therapeutics 1982, 19 (2), 245-295.

44. Frayha, G. J.; Smyth, J.; Gobert, J. G.; Savel, J., The mechanisms of action of antiprotozoal and anthelmintic drugs in man. General Pharmacology: The Vascular System 1997, 28 (2), 273-299.

45. Patgiri, A.; Skinner, O. S.; Miyazaki, Y.; Schleifer, G.; Marutani, E.; Shah, H.; Sharma, R.; Goodman, R. P.; To, T. L.; Robert Bao, X.; Ichinose, F.; Zapol, W. M.; Mootha, V. K., An engineered enzyme that targets circulating lactate to alleviate intracellular NADH:NAD(+) imbalance. Nat Biotechnol 2020, 38 (3), 309-313.

46. Strieder, V.; Lutz, W., E2F proteins regulate MYCN expression in neuroblastomas. J Biol Chem 2003, 278 (5), 2983-9.

47. Metallo, C. M.; Gameiro, P. A.; Bell, E. L.; Mattaini, K. R.; Yang, J.; Hiller, K.; Jewell, C. M.; Johnson, Z. R.; Irvine, D. J.; Guarente, L.; Kelleher, J. K.; Vander Heiden, M. G.; Iliopoulos, O.; Stephanopoulos, G., Reductive glutamine metabolism by IDH1 mediates lipogenesis under hypoxia. Nature 2011, 481 (7381), 380-4.

48. Mullen, A. R.; Wheaton, W. W.; Jin, E. S.; Chen, P. H.; Sullivan, L. B.; Cheng, T.; Yang, Y.; Linehan, W. M.; Chandel, N. S.; DeBerardinis, R. J., Reductive carboxylation supports growth in tumour cells with defective mitochondria. Nature 2011, 481 (7381), 385-8.

49. Wise, D. R.; Ward, P. S.; Shay, J. E.; Cross, J. R.; Gruber, J. J.; Sachdeva, U. M.; Platt, J. M.; DeMatteo, R. G.; Simon, M. C.; Thompson, C. B., Hypoxia promotes isocitrate dehydrogenase-dependent carboxylation of alpha-ketoglutarate to citrate to support cell growth and viability. Proc Natl Acad Sci U S A 2011, 108 (49), 19611-6.

50. Nordsmark, M.; Overgaard, M.; Overgaard, J., Pretreatment oxygenation predicts radiation response in advanced squamous cell carcinoma of the head and neck. Radiother Oncol 1996, 41 (1), 319.

51. Hockel, M.; Schlenger, K.; Mitze, M.; Schaffer, U.; Vaupel, P., Hypoxia and Radiation Response in Human Tumors. Seminars in radiation oncology 1996, 6 (1), 3-9. 
52. Teicher, B. A.; Holden, S. A.; al-Achi, A.; Herman, T. S., Classification of antineoplastic treatments by their differential toxicity toward putative oxygenated and hypoxic tumor subpopulations in vivo in the FSallC murine fibrosarcoma. Cancer research 1990, 50 (11), 3339-44.

53. Wike-Hooley, J. L.; Haveman, J.; Reinhold, H. S., The relevance of tumour pH to the treatment of malignant disease. Radiother Oncol 1984, 2 (4), 343-66.

54. Sutherland, R. M.; Eddy, H. A.; Bareham, B.; Reich, K.; Vanantwerp, D., Resistance to adriamycin in multicellular spheroids. International journal of radiation oncology, biology, physics 1979, 5 (8), 1225 30.

55. Tao, H.; Zhang, Y.; Zeng, X.; Shulman, G. I.; Jin, S., Niclosamide ethanolamine-induced mild mitochondrial uncoupling improves diabetic symptoms in mice. Nat Med 2014, 20 (11), 1263-9.

56. Niemas-Teshiba, R.; Matsuno, R.; Wang, L. L.; Tang, X. X.; Chiu, B.; Zeki, J.; Coburn, J.; Ornell, K.; Naranjo, A.; Van Ryn, C., MYC-family protein overexpression and prominent nucleolar formation represent prognostic indicators and potential therapeutic targets for aggressive high-MKI neuroblastomas: a report from the children's oncology group. Oncotarget 2018, 9 (5), 6416.

57. Warburg, O.; Wind, F.; Negelein, E., The Metabolism of Tumors in the Body. The Journal of general physiology 1927, 8 (6), 519-30.

58. Warburg, O., On the origin of cancer cells. Science 1956, 123 (3191), 309-14.

59. Dang, L.; White, D. W.; Gross, S.; Bennett, B. D.; Bittinger, M. A.; Driggers, E. M.; Fantin, V. R.; Jang, H. G.; Jin, S.; Keenan, M. C.; Marks, K. M.; Prins, R. M.; Ward, P. S.; Yen, K. E.; Liau, L. M.; Rabinowitz, J. D.; Cantley, L. C.; Thompson, C. B.; Vander Heiden, M. G.; Su, S. M., Cancer-associated IDH1 mutations produce 2-hydroxyglutarate. Nature 2009, 462 (7274), 739-44.

60. Ward, P. S.; Patel, J.; Wise, D. R.; Abdel-Wahab, O.; Bennett, B. D.; Coller, H. A.; Cross, J. R.; Fantin, V. R.; Hedvat, C. V.; Perl, A. E.; Rabinowitz, J. D.; Carroll, M.; Su, S. M.; Sharp, K. A.; Levine, R. L.; Thompson, C. B., The common feature of leukemia-associated IDH1 and IDH2 mutations is a neomorphic enzyme activity converting alpha-ketoglutarate to 2-hydroxyglutarate. Cancer Cell 2010, 17 (3), 225-34.

61. Xu, W.; Yang, H.; Liu, Y.; Yang, Y.; Wang, P.; Kim, S. H.; Ito, S.; Yang, C.; Wang, P.; Xiao, M. T.; Liu, L. X.; Jiang, W. Q.; Liu, J.; Zhang, J. Y.; Wang, B.; Frye, S.; Zhang, Y.; Xu, Y. H.; Lei, Q. Y.; Guan, K. L.; Zhao, S. M.; Xiong, Y., Oncometabolite 2-hydroxyglutarate is a competitive inhibitor of alpha-ketoglutaratedependent dioxygenases. Cancer Cell 2011, 19 (1), 17-30.

62. Shim, E. H.; Livi, C. B.; Rakheja, D.; Tan, J.; Benson, D.; Parekh, V.; Kho, E. Y.; Ghosh, A. P.; Kirkman, R.; Velu, S.; Dutta, S.; Chenna, B.; Rea, S. L.; Mishur, R. J.; Li, Q.; Johnson-Pais, T. L.; Guo, L.; Bae, S.; Wei, S.; Block, K.; Sudarshan, S., L-2-Hydroxyglutarate: an epigenetic modifier and putative oncometabolite in renal cancer. Cancer Discov 2014, 4 (11), 1290-8.

63. Figueroa, M. E.; Abdel-Wahab, O.; Lu, C.; Ward, P. S.; Patel, J.; Shih, A.; Li, Y.; Bhagwat, N.; Vasanthakumar, A.; Fernandez, H. F.; Tallman, M. S.; Sun, Z.; Wolniak, K.; Peeters, J. K.; Liu, W.; Choe, S. E.; Fantin, V. R.; Paietta, E.; Lowenberg, B.; Licht, J. D.; Godley, L. A.; Delwel, R.; Valk, P. J.; Thompson, C. B.; Levine, R. L.; Melnick, A., Leukemic IDH1 and IDH2 mutations result in a hypermethylation phenotype, disrupt TET2 function, and impair hematopoietic differentiation. Cancer Cell 2010, 18 (6), 553-67.

64. Lu, C.; Ward, P. S.; Kapoor, G. S.; Rohle, D.; Turcan, S.; Abdel-Wahab, O.; Edwards, C. R.; Khanin, R.; Figueroa, M. E.; Melnick, A.; Wellen, K. E.; O'Rourke, D. M.; Berger, S. L.; Chan, T. A.; Levine, R. L.; Mellinghoff, I. K.; Thompson, C. B., IDH mutation impairs histone demethylation and results in a block to cell differentiation. Nature 2012, 483 (7390), 474-8.

65. Thiele, C. J.; Reynolds, C. P.; Israel, M. A., Decreased expression of N-myc precedes retinoic acidinduced morphological differentiation of human neuroblastoma. Nature 1985, 313 (6001), 404-6. 


\section{Figure 1}

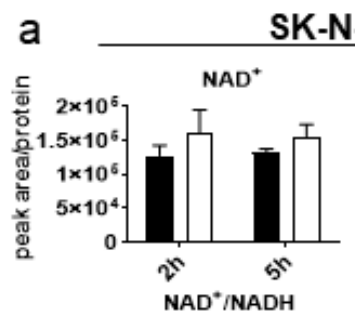

SK-N-BE(2)
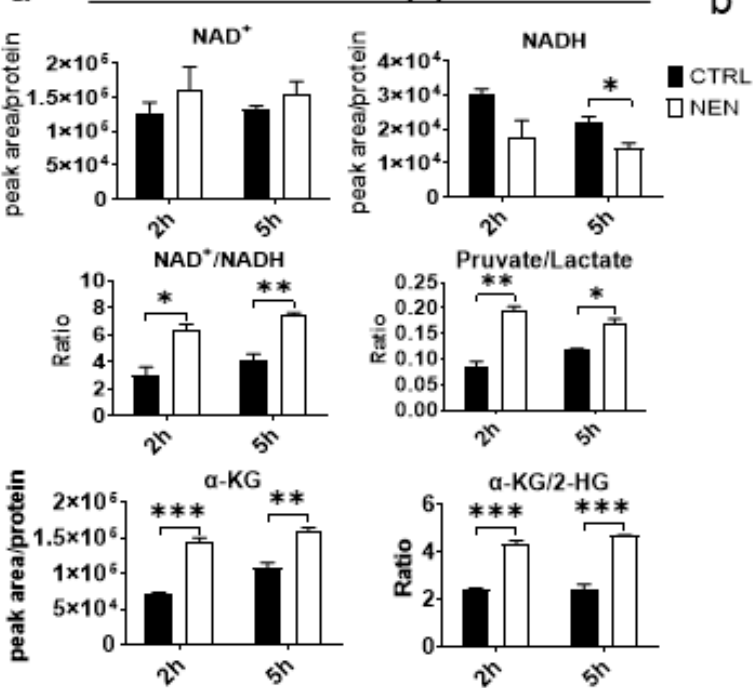

Pruvate/Lactate
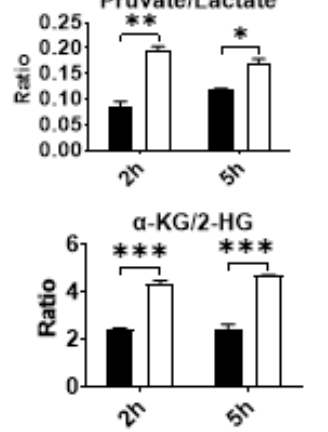

b
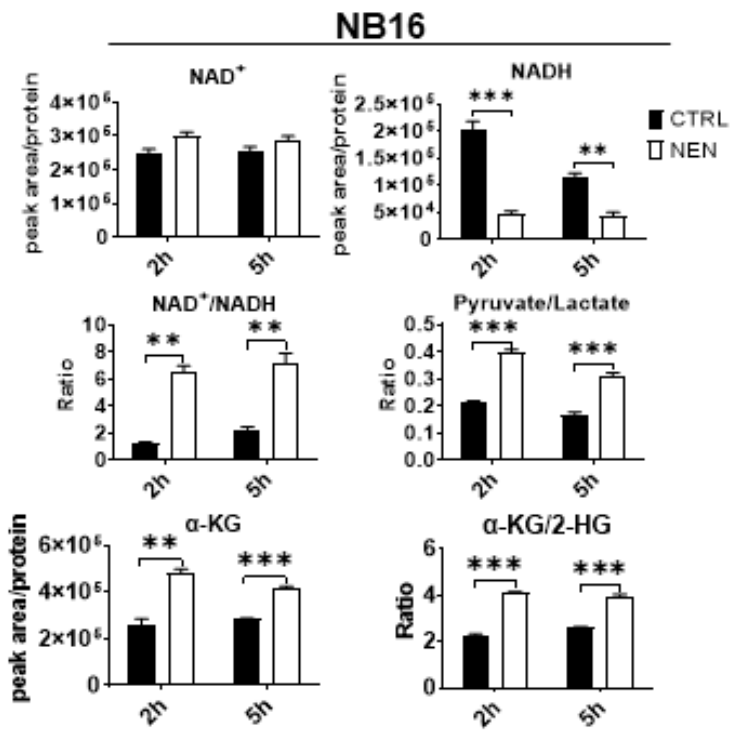

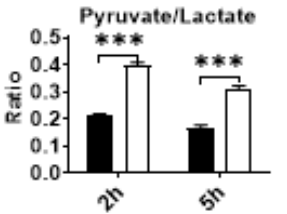

a-KG/2-HG

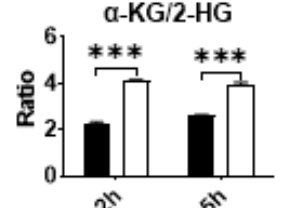

d SK-NB-E(2)
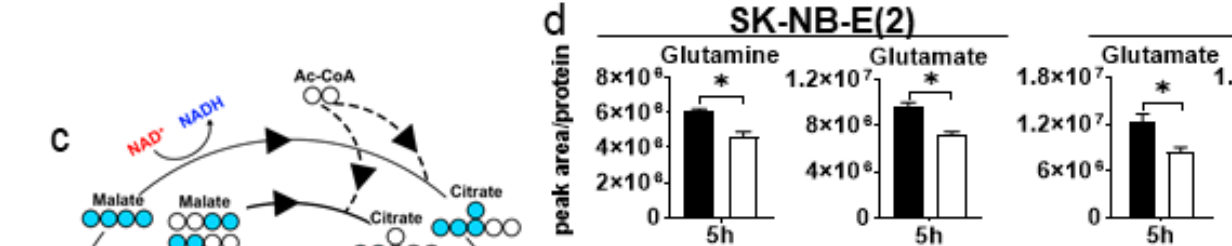

NB16

Glutamine
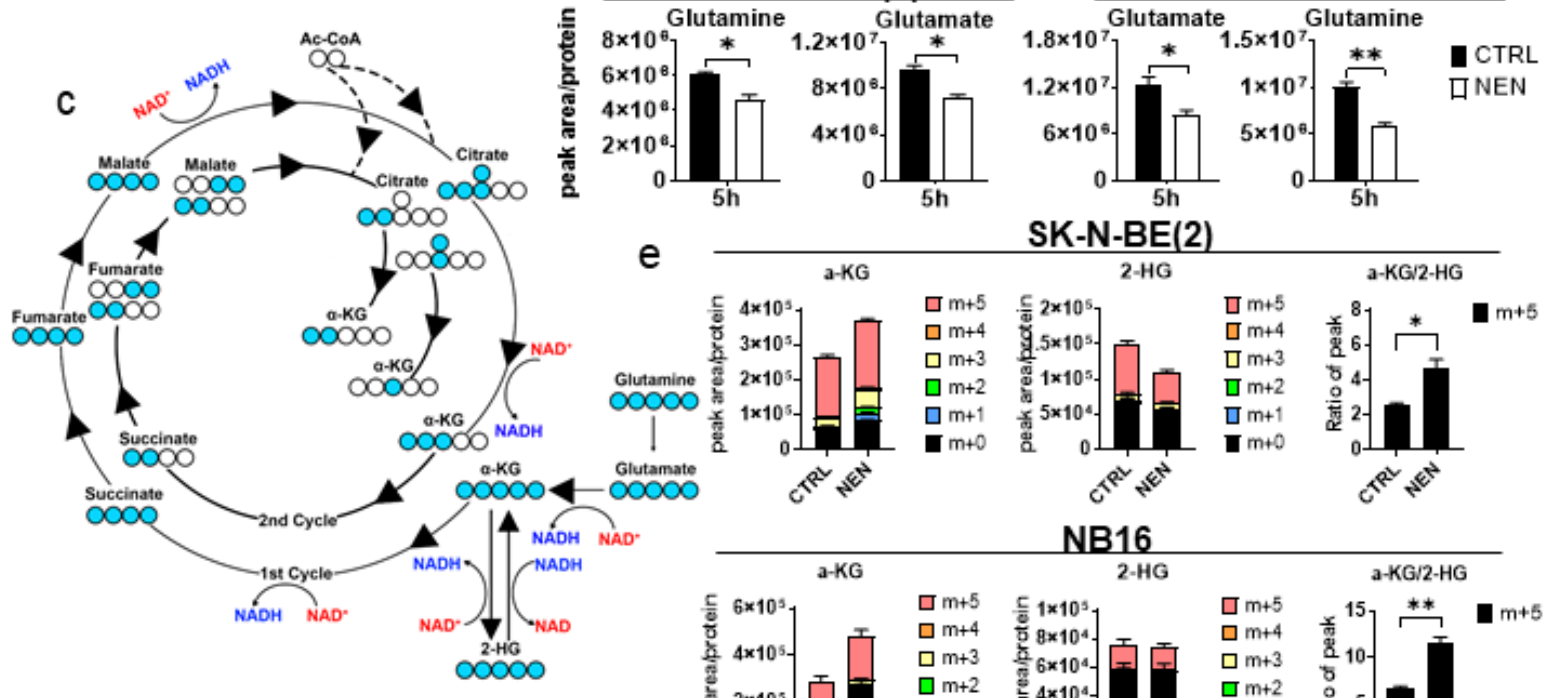

e

SK-N-BE(2)

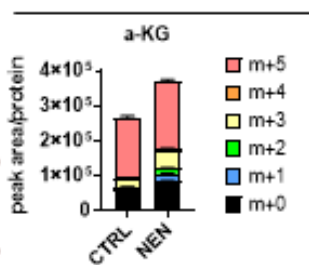

\section{$2-\mathrm{HG}$}

$\square m+5$

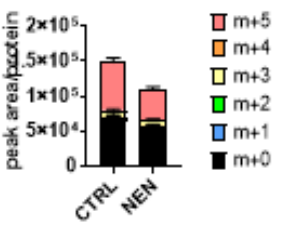

$\mathrm{a}-\mathrm{KG} / 2-\mathrm{HG}$

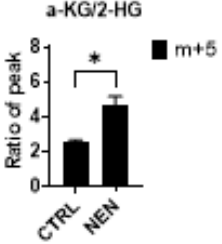

NB16
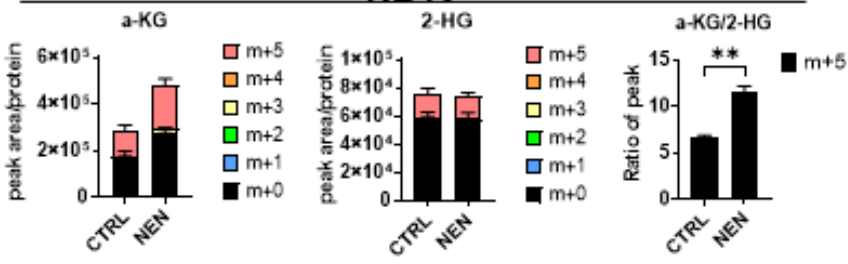

Figure 1. NEN treatment accelerates glutaminolysis to increase cellular aKG.

Relative intracellular metabolite levels were measured using LC/MS in SK-N-BE(2) cells (a) and NB16 cells (b) treated with DMSO or $1 \mu \mathrm{M} N E N$ for $2 \mathrm{~h}$ or $5 \mathrm{~h}$. (c) Relative intracellular L-glutamine and Lglutamate levels were measured using LC/MS in SK-N-BE(2) cells and NB16 cells treated with DMSO or $1 \mu \mathrm{M} \mathrm{NEN}$ for $5 \mathrm{~h}$. (d) Schematic of ${ }^{13} \mathrm{C}$-labeling patterns of TCA cycle metabolites froi $\mathrm{U}-{ }^{13} \mathrm{C}$ glutamine. (e) SK-N-BE(2) and NB16 cells were pretreated by DMSO or $1 \mu \mathrm{M}$ NEN for 3h, then labeled with $\mathrm{U}-{ }^{13} \mathrm{C}$-glutamine for $2 \mathrm{~h}$. Relative isotopic labelling abundance in $\alpha K G, 2 \mathrm{HG}$ and the ratio of $\mathrm{m}+5$ $\alpha K G / m+52 H G$ were measured using LC/MS. Data represent mean $\pm \operatorname{SEM}(n=3$, biologically repeats). Representative of at least two independent experiments. ${ }^{*} \mathrm{P}<0.05,{ }^{\star *} \mathrm{P}<0.01$, ${ }^{\star \star *} \mathrm{P}<0.001$. Two-sided Student's t-test. 
Figure 2

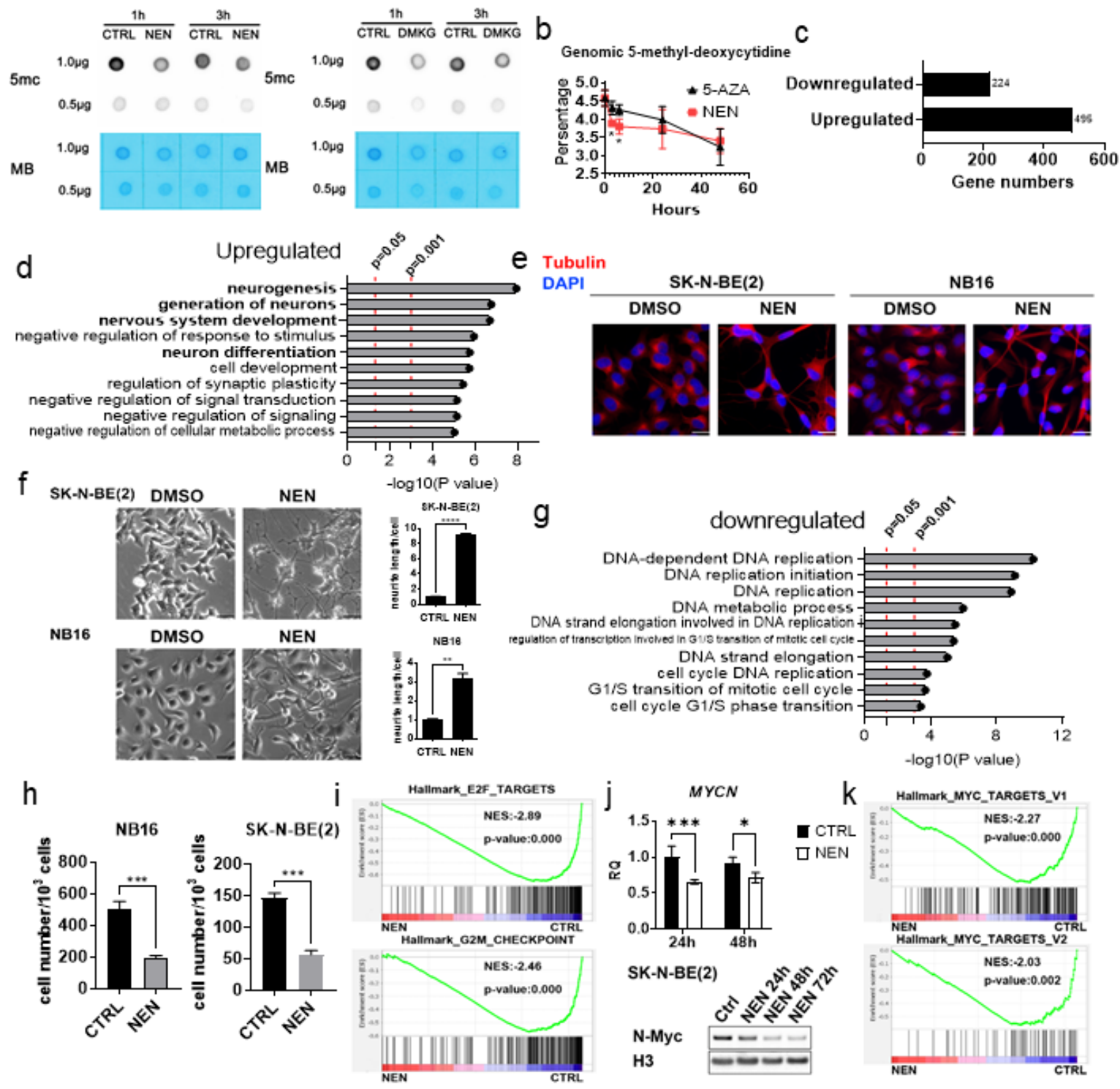

Figure 2. NEN decreased global DNA methylation and promote neuron differentiation.

(a) Global DNA methylation in NB16 cells treated with DMSO, $1 \mu \mathrm{M}$ NEN or 3.5mM DMKG for 1 hrs and 3hrs was measured using dot blot. (b) Quantification of global DNA methylation in SK-N-BE(2) cells treated by DMSO, $1 \mu \mathrm{M}$ NEN or $1 \mu \mathrm{M}$ 5-AZA for $3 \mathrm{~h}, 6 \mathrm{~h}, 24 \mathrm{~h}$ and $48 \mathrm{~h}$ by using the MethylFlash ${ }^{\text {TM }}$ Global DNA Methylation (5-mC) ELISA Easy Kit . (c) Number of genes differentially expressed after NEN treatment for $16 \mathrm{hrs}$ in SK-N-BE(2) cells with a sleuth qvalue $<0.05$ and fold change estimate $b>a b s(\ln (2))$. (d) The top 10 gene expression signature pathways enriched from upregulated genes from David analysis. (e) Immunofluorescence staining of $\beta$-tubulin III(Red) and DAPI (Blue) in SK-N-EB(2) and NB16 cells treated by DMSO, $1 \mu \mathrm{M}$ NEN for $72 \mathrm{~h}$. Scale bar: $25 \mu \mathrm{m}$. (f) Left: morphological feature of NB16 and SK-N-BE(2) cells treated by DMSO or $1 \mu \mathrm{M} \mathrm{NEN} \mathrm{for} 96 \mathrm{~h}$ (Scale bar: $50 \mu \mathrm{M})$. Right: Quantification of neurite outgrowth with NeuronJ. (g) The top 10 gene expression signatures enriched from downregulated genes from

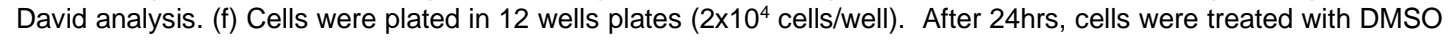
or $1 \mu \mathrm{M}$ NEN for 3 days, and then counted. (i) GSEA of E2F targets and G2M checkpoints pathways genes from the RNA-seq $(n=3)$ experiments in SK-N-BE(2) cells. (j) mRNA and protein levels of N-myc were examined in SK-N-BE(2) cells treated with $1 \mu \mathrm{M}$ NEN for indicated time. (k) GSEA of N-myc targets pathway genes from the RNA-seq $(n=3)$ experiments in SK-N-BE(2) cells. 


\section{Figure 3}

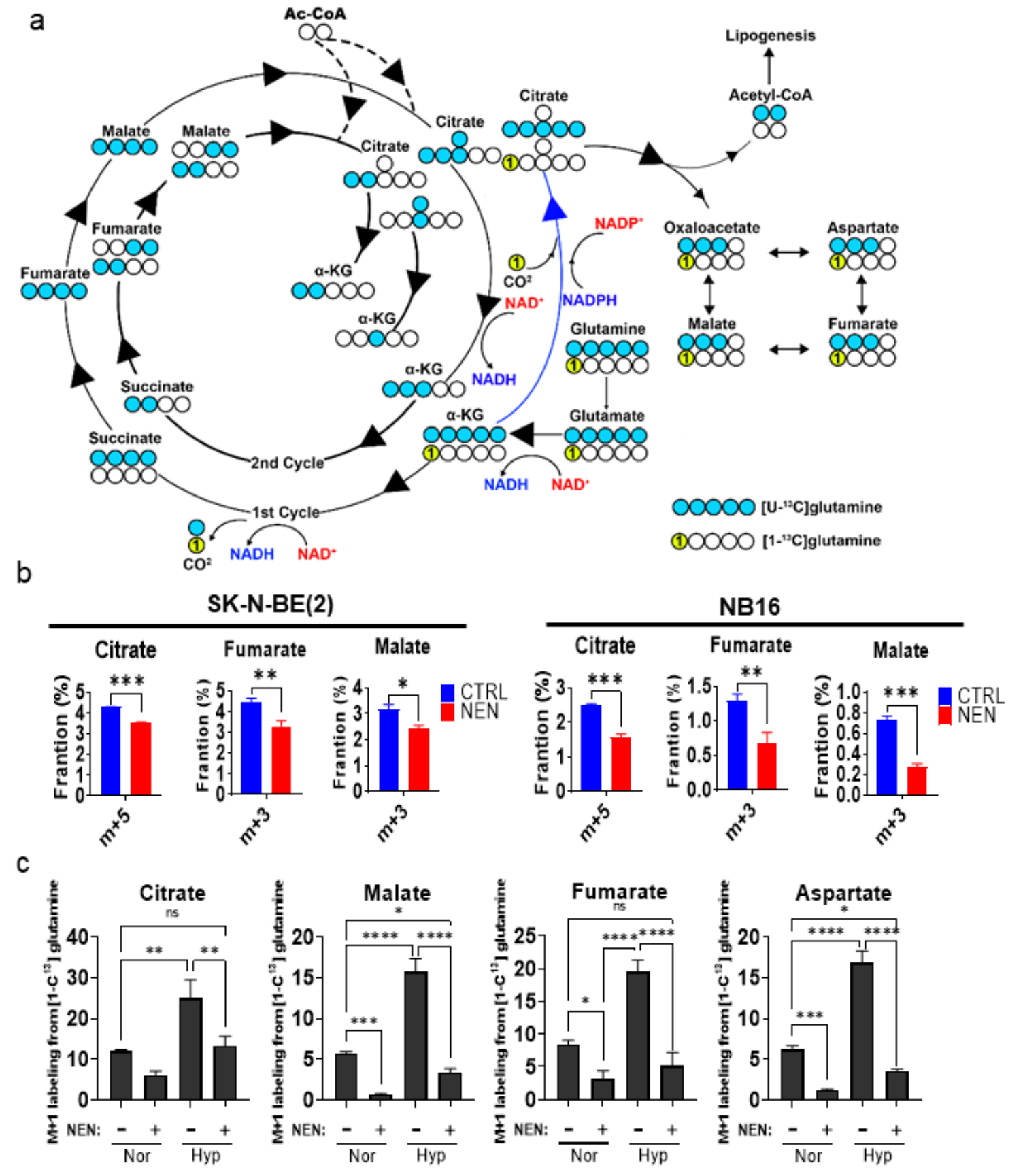

Figure 3. NEN treatment decreased the reductive carboxylation.

(a) Schematic of carbon atom (circles) transitions from $\mathrm{U}-{ }^{13} \mathrm{C}$-glutamine(blue) and $1{ }^{13} \mathrm{C}$ glutamine (yellow) into oxidation TCA cycle or reductive carboxylation. (b) SK-N-BE(2) and NB16 cells were pretreated by DMSO or $1 \mu \mathrm{M}$ $\mathrm{NEN}$ for $3 \mathrm{~h}$, then switched to medium contained same treatment in the presence of $\mathrm{U}-{ }^{13} \mathrm{C}$-glutamine for $2 \mathrm{~h}$. The Isotopomer distribution of citrate, malate, fumarate and aspartate from $\mathrm{U}-{ }^{13} \mathrm{C}$-glutamine were measured using LC/MS. (c) SK-N-BE(2) cells were pretreated by DMSO or $1 \mu \mathrm{M} \mathrm{NEN} \mathrm{for} 3 \mathrm{~h}$ under normoxia or hypoxia ( $0.5 \%$ oxygen), then switched to medium contained same treatment in the presence of $1{ }^{13} \mathrm{C}$-glutamine for $3 \mathrm{~h}$. The Isotopomer distribution of citrate, malate and fumarate were measured using LC/MS. Data represent the mean \pm SEM from three biologically repeats. ${ }^{*} \mathrm{P}<0.05,{ }^{* *} \mathrm{P}<0.01$ and ${ }^{* * *} \mathrm{P}<0.001$. Two-sided Student's t-test.. 


\section{Figure 4}

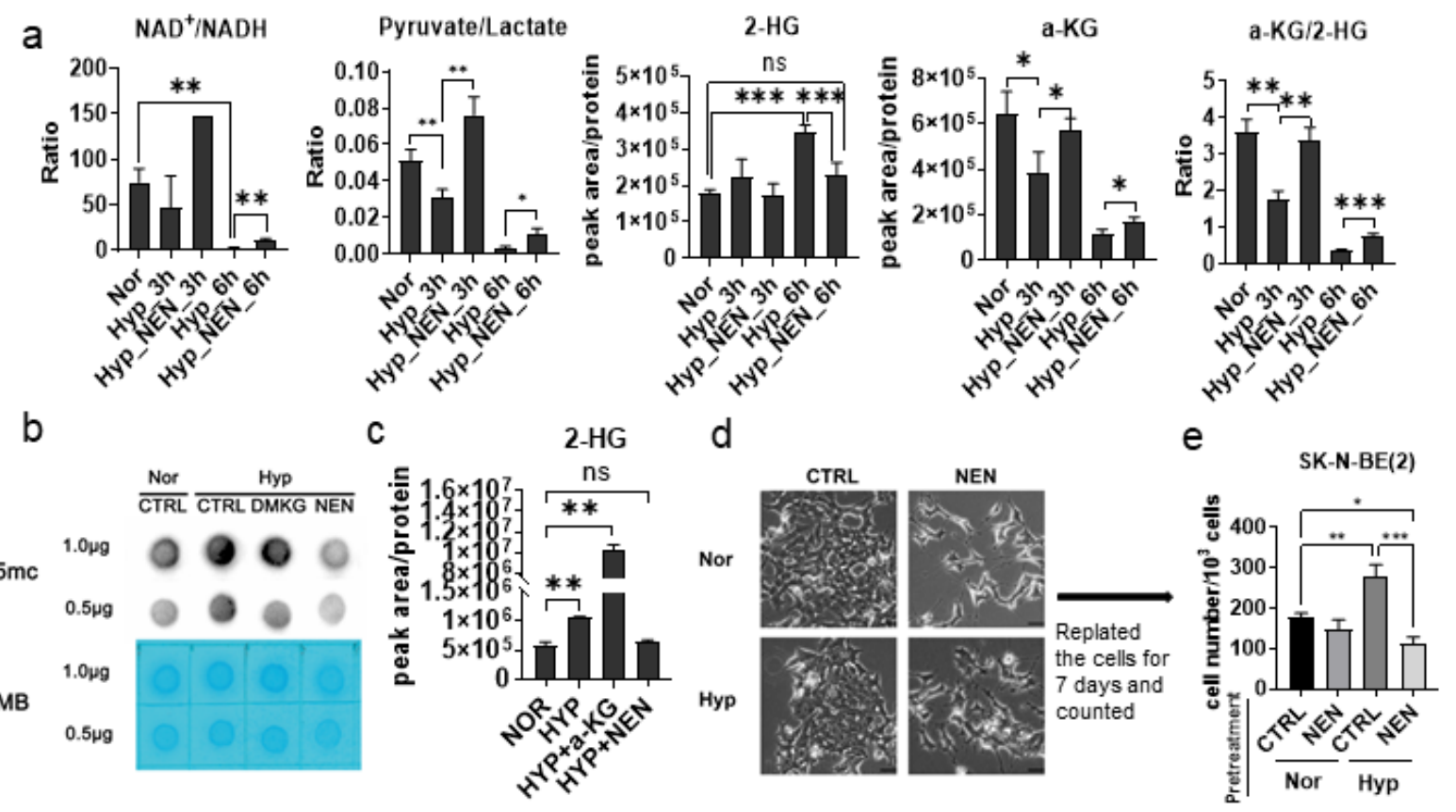

Figure 4 NEN inhibit 2-HG generation and DNA hypermethylation under hypoxia

(a) Relative Intracellular metabolite level or ratio were measured by LC/MS in SK-N-BE(2) cells treated by DMSO under normoxia or DMSO / $1 \mu \mathrm{M}$ NEN under hypoxia for $3 \mathrm{~h}$ or $6 \mathrm{~h}$. (b) Morphological feature of SK-N-BE(2) cells treated by DMSO or $1 \mu \mathrm{M}$ NEN under normoxia or hypoxia for 4 days(Scale bar: $50 \mu \mathrm{M}$ ). (c) Trypsinized the cells from (b) and replated 2x104 cells/well were plated in 12 wells plates. Count the cells after 5 days. (d) Analysis and quantification of global DNA methylation in CHP134 cells treated by DMSO or $1 \mu \mathrm{M}$ NEN or 3.5mM DMKG under normoxia or hypoxia for 6hrs by using dot blot. (e) Relative Intracellular 2-HG level were measured by LC/MS in CHP134 cells treated by DMSO or $1 \mu \mathrm{M}$ NEN or 3.5mM DMKG under normoxia or hypoxia for 5 hrs. Data are the mean \pm SEM from $n=3$ biologically independent. ${ }^{*} P<0.05{ }^{* *} P<0.01$ and ${ }^{* \star *} P<0.00$ for comparisons were calculated using a two-sided Student's t-test. 


\section{Figure 5}

a

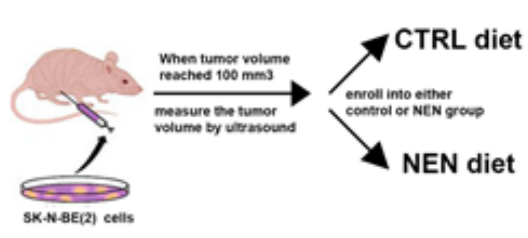

e

H\&E

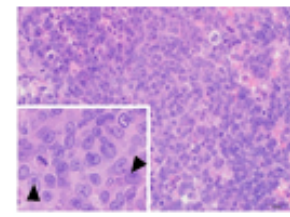

b Plasma NEN concentration

C Tissue NEN d accumulation Time to reach tumor volume indicated

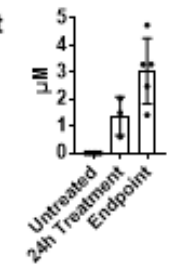
|

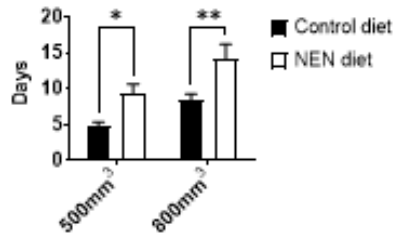

f Ctrl NEN

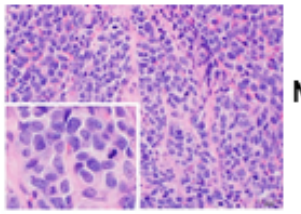

N-Myc
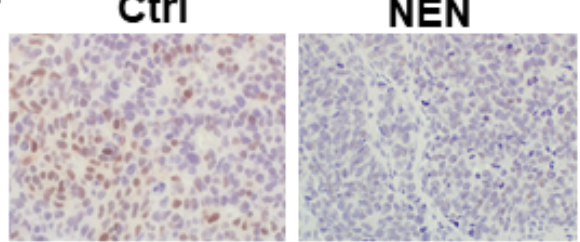

Figure 5. NEN supplementation inhibits growth of orthotropic neuroblastoma in vivo

(a) The schematic of in vivo experiment $(b, c)$ The plasma and tissue NEN accumulation were measured by LC/MS. (d) Quantification of time to reach certain tumor volume on CTRL group $(n=6)$ and NEN group $(n=4)$. (e) Nucleolar formation in the tumors cells were examined by H\&E staining in both CTRL and Treatment group. The arrows point out the prominent nucleolar formation. (f) The tumors in both CTRL and NEN treatment group were stained with H\&E and processed for N-Myc immunohistochemistry staining. 


\section{Figure 6}

a

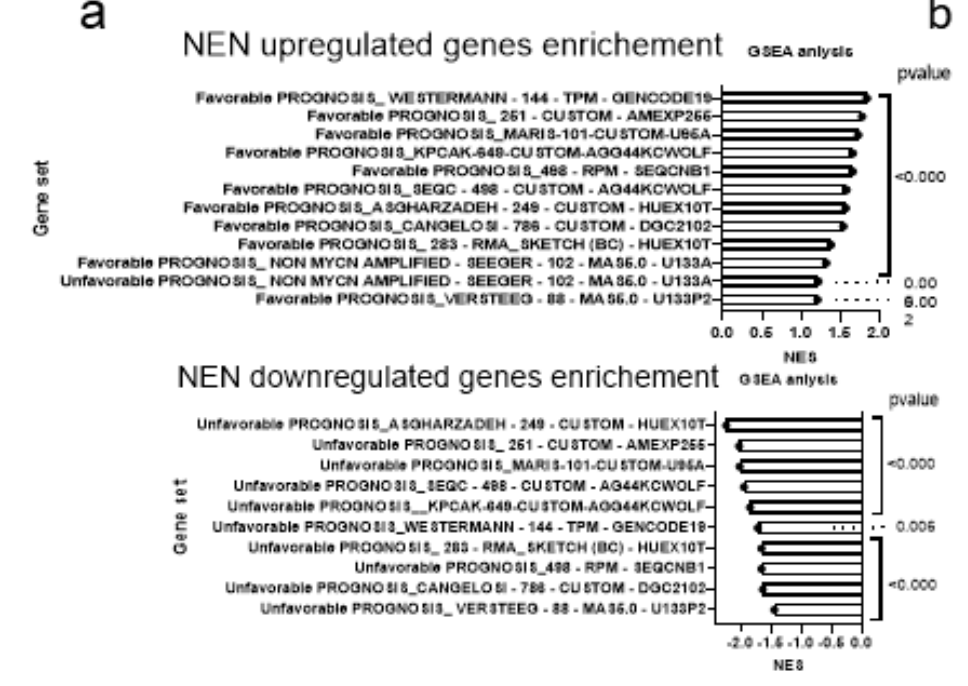

C

\section{Favorable prognosis}
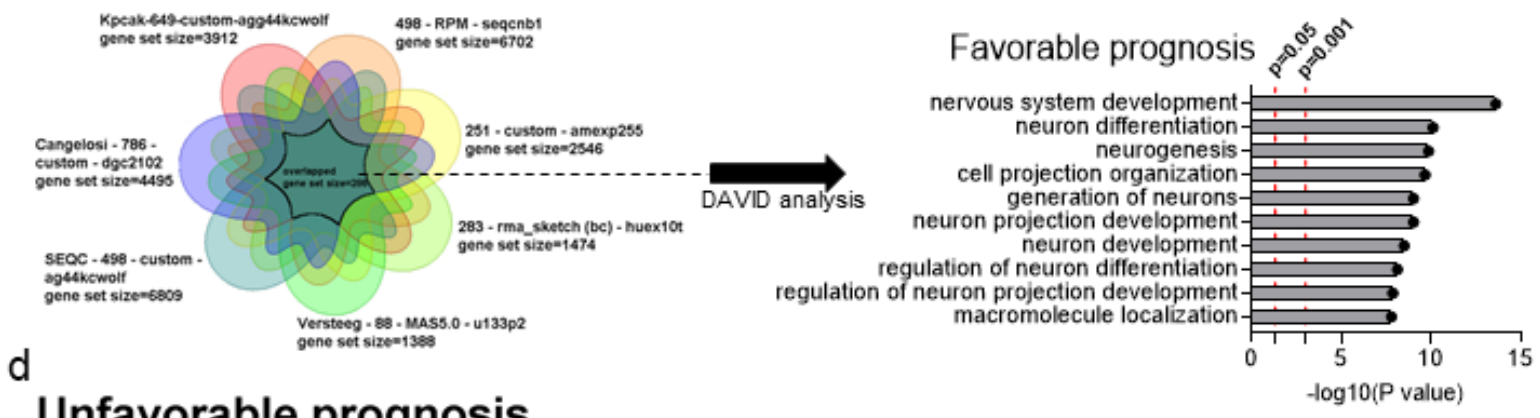

Unfavorable prognosis
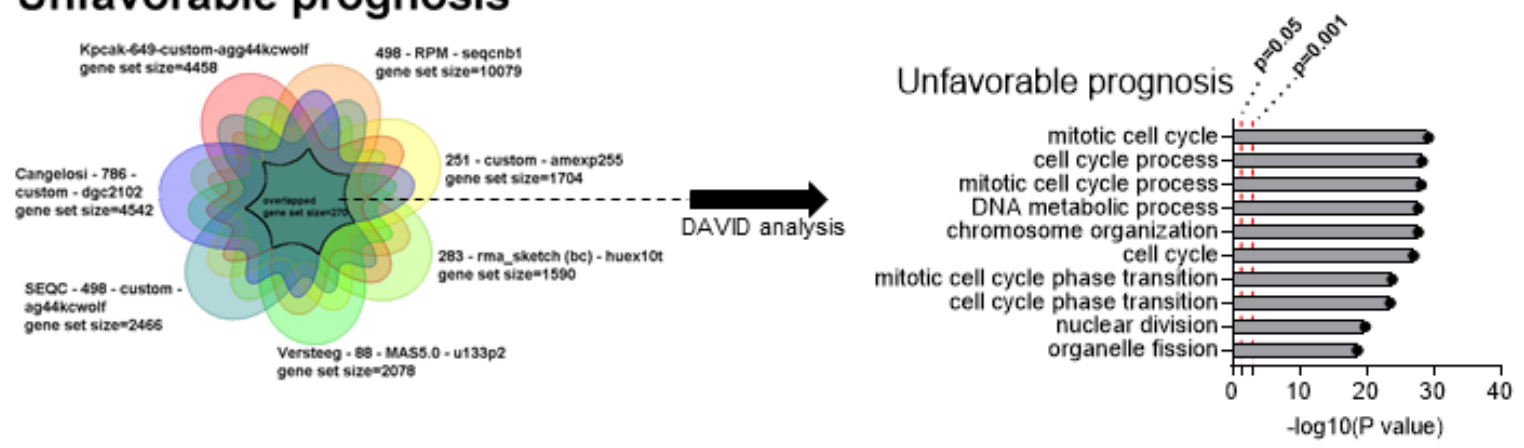

Figure 6 NEN showed favorable prognosis potential

(a) The gene expression data generated by RNA-seq $(n=3)$ was analyzed by using GSEA to perform enrichment in SK-N-BE(2) cells. The gene sets (good or bad prognosis, pvalue<0.05) were defined from 11 available neuroblastoma databases from R2 (https://hgserver1.amc.nl/cgi-bin/r2/main.cgi). (b) Represented analysis plot from (a). (c) Overlap the good prognosis gene sets ( $p$-value $<0.05$, gene number $>1000$ ) from 7 available neuroblastoma databases from R2 (https://hgserver1.amc.nl/cgi-bin/r2/main.cgi). And the overlapped genes were submitted to David analysis. (d) Overlap the bad prognosis gene sets ( $p$-value $<0.05$, gene number $>1000)$ from 7 available neuroblastoma databases from R2 (https://hgserver1.amc.nl/cgi-bin/r2/main.cgi). And the overlapped genes were submitted to David analysis. 
Figure S1

a SK-N-BE(2)

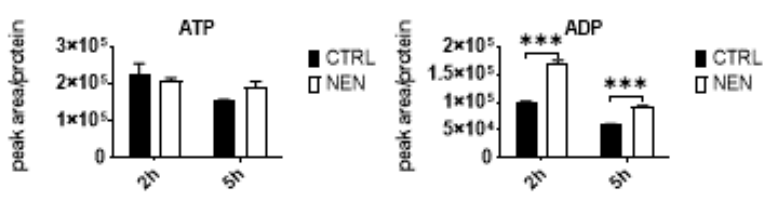

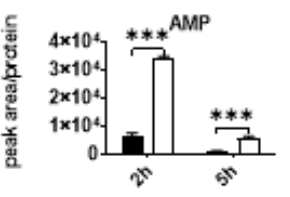

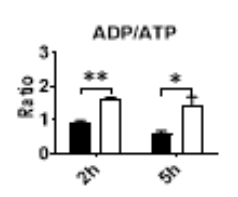

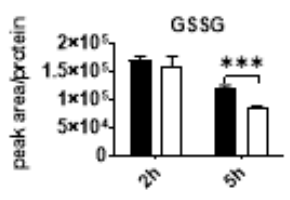
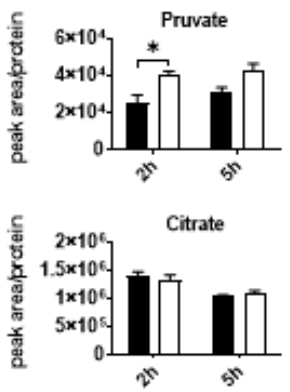

CTRL
पNEN

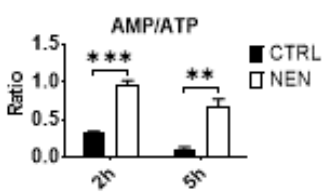

UCTRL 营
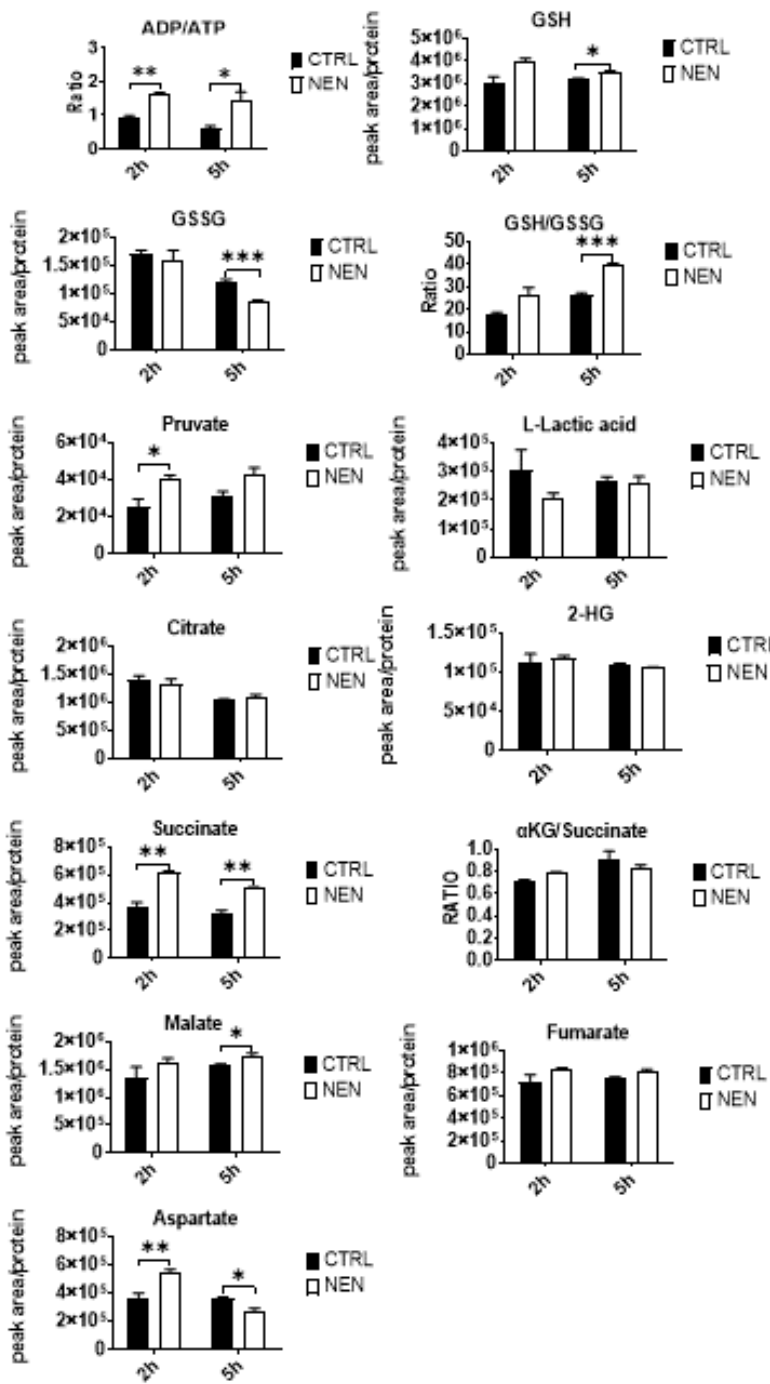

\section{b NB16}
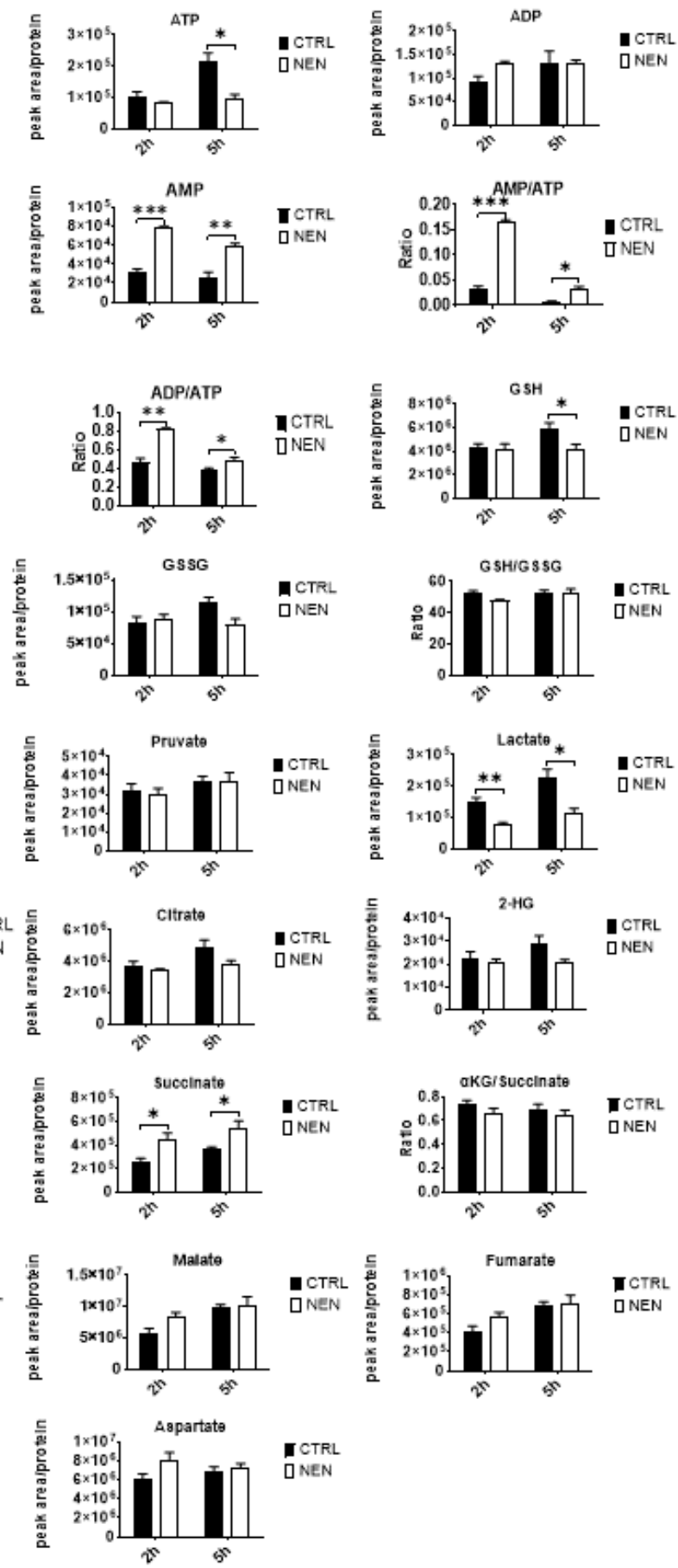

Figure S1 The metabolic profiling upon NEN treatment

Relative intracellular metabolite levels of the same samples in figure $1 \mathrm{a}$ and $\mathrm{b}$. Data represent mean $\pm \mathrm{SEM}(\mathrm{n}=3$, biologically repeats). Representative of at least two independent experiments. ${ }^{*} \mathrm{P}<0.05,{ }^{* \star} \mathrm{P}<0.01$, ${ }^{\star *} \mathrm{P}<0.001$. Two-sided Student's t-test. 


\section{Figure S2}

a

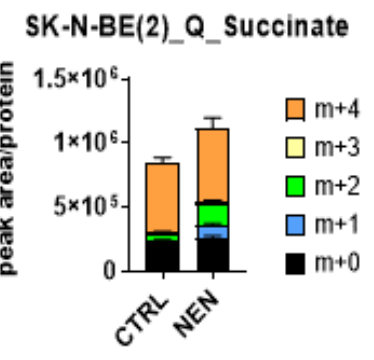

b

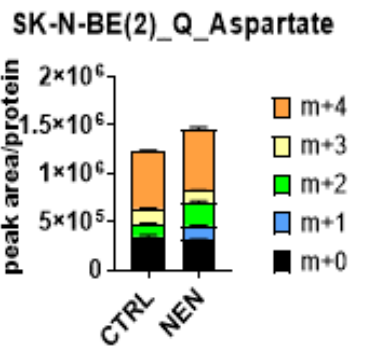

NB16_Q_Succinate

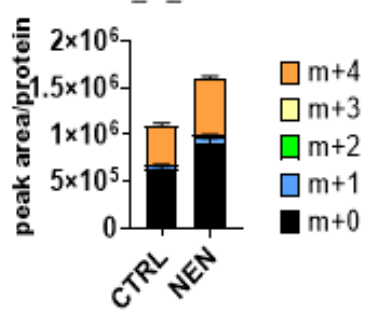

NB16_Q_Aspartate

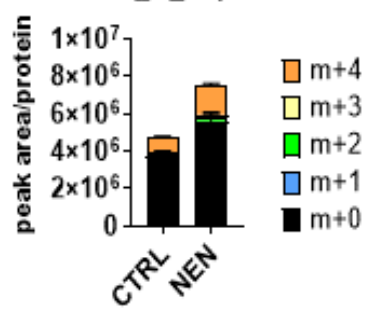

Figure S2 NEN treatment reprograms glutamine metabolism.

(a) SK-N-BE(2) and NB16 cells were pretreated by DMSO or $1 \mu \mathrm{M}$ NEN for $3 \mathrm{~h}$, then change the medium contained same treatment in the presence of $U-1^{3} \mathrm{C}$-glutamine for $2 \mathrm{~h}$. Data represent mean $\pm S E M(n=3$, biologically repeats). Representative of at least two independent experiments. ${ }^{*} \mathrm{P}<0.05{ }^{* *} \mathrm{P}<0.01$ and ${ }^{* * *} \mathrm{P}<0.001$ Two-sided Student's t-test. 


\section{Figure S3}
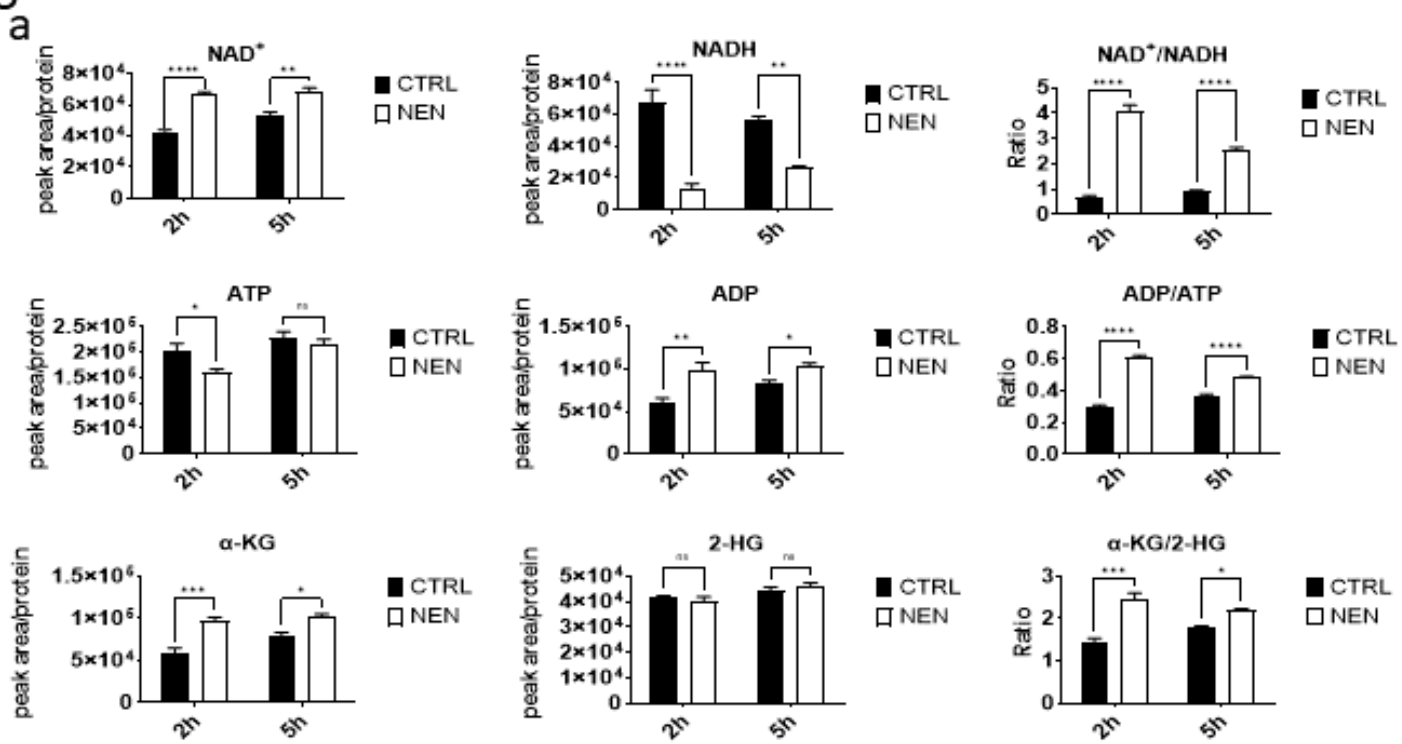

b
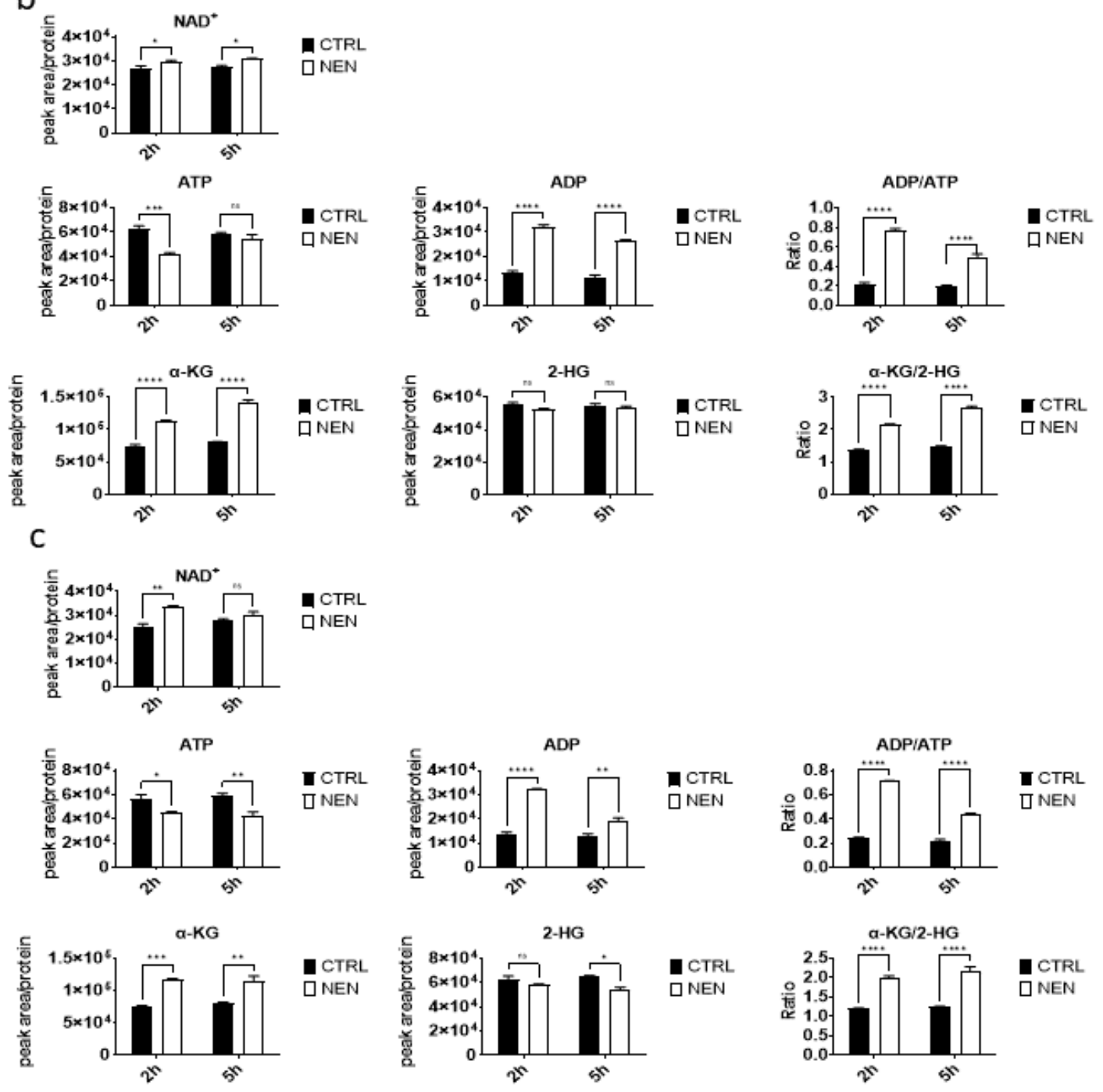
bioRxiv preprint doi: https://doi.org/10.1101/2021.09.05.459035; this version posted September 6, 2021. The copyright holder for this preprint (which was not certified by peer review) is the author/funder. All rights reserved. No reuse allowed without permission.

Figure S3 The metabolic reprograming effect of NEN on other cancer cell types.

Relative intracellular metabolite level or ratios were measured using LC/MS in (a) Ovcar3 cells, (b)H29 and (c) H82 cells. Cells were treated with DMSO or $1 \mu \mathrm{M} N E N$ for $2 \mathrm{~h}$ or $5 \mathrm{~h}$. Data represent mean $\pm \operatorname{SEM}(\mathrm{n}=3$, biologically repeats). Representative of at least two independent experiments. ${ }^{*} P<0.05{ }^{* \star} \mathrm{P}<0.01$ and ${ }^{* \star *} \mathrm{P}<0.001$. Two-sided Student's t-test. 


\section{Figure S4}

a

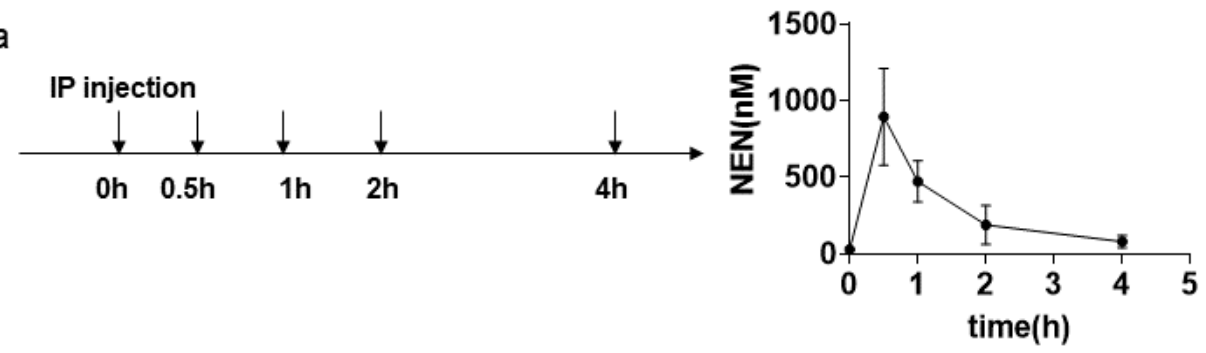

Figure S4 Plasma pharmacokinetics of NEN after through intraperitoneal injection.

(a) $250 \mu \mathrm{g}$ NEN in DMSO were delivered to the mouses through intraperitoneal injection. Blood collection were performed for indicated time by tail vein sampling. The NEN concentration were measured by LC-MS $(n=3)$. 